\title{
Experimental investigation of quasi-static behavior of composite and fiber metal laminate panels modified by graphene-nanoplatelets
}

\author{
Azadeh Fathi ${ }^{1}$, Gholamhossein Liaghat ${ }^{1,2, *}$, Hadi Sabouri ${ }^{3}$, Mahmoud Chizari ${ }^{4}$, Homayoun \\ Hadavinia $^{2}$, Sahand Chitsaz Charandabi ${ }^{5}$
}

\begin{abstract}
:
The current study investigated the influence of incorporation of graphene nanoplatelets (GNPs) on quasi-static behavior of composite and fiber metal laminate (FML) panels. The unmodified and modified composite specimens and FML panels with 2/1 configuration were fabricated using a hand lay-up method and investigated through a quasi-static punch and indentation testing. The two sets of tests were conducted with a flat-ended indenter and the loading conditions were the same for all samples, except support spans which were varied. Following experimental testing, possible damages at the punch region were closely investigated and localized and global damages were observed. The results revealed that adding $0.2 \mathrm{wt} \%$ GNPs improved the strength and fracture toughness of specimens by delaying the failure modes. On the contrary, GNPs made the bonding between the aluminum and composite interface weaken.
\end{abstract}

Keywords: Composite, Fiber metal laminate, Graphene nanoplatelets, Quasi-Static, Punch, Indentation

\footnotetext{
${ }^{1}$ Department of Mechanical Engineering, Faculty of Engineering, Tarbiat Modares University, Tehran, Iran ${ }^{2}$ School of Mechanical \& Aerospace Engineering, Kingston University, London, UK

${ }^{3}$ Department of Mechanical Engineering, Faculty of Engineering, Kharazmi University, Tehran, Iran

${ }^{4}$ Department of Engineering, University of Hertfordshire, Hatfield, UK

${ }^{5}$ School of Mechanical Engineering, Coventry University, Coventry, UK

*Corresponding author:

Department of Mechanical Engineering, Tarbiat Modares University, Tehran, Iran.

E-mail: Ghlia530@modares.ac.ir, G.Liaghat@kingston.ac.uk (G. Liaghat).
} 


\section{Introduction}

FMLs are fiber metal laminates that consist of thin metal layers bonded with composite material laminates. The outstanding properties of FMLs, such as an ability to delay and stop crack growth, high damage tolerance, high strength and low density cause to be used in industrial structures. With these characteristics, the engineers became interested in the application of FMLs in aircraft structures. For example, FMLs were used in the fuselage skin structures of Airbus A380 (22\% of the primary structures in the Airbus A380 are made from GLAss REinforced aluminum laminates-GLARE). In the 1950s, researches performed by Fokker Aircraft Corporation showed that bonding between metal and composite would prevent the rapid fatigue crack growth, which could significantly improve the construction of the aircraft's body. A few years later, in 1980, at the University of Delft, composite and metal bonding were investigated and an optimized FML called ARALL (Aramid Reinforced ALuminum Laminate) was developed..$^{1-4}$

The original patents on the FML concept and corresponding method have been filed by Schijve et al. ${ }^{5}$ in 1981-1982. Moreover, the first commercial product of FML was launched by ALCOA in 1982 and a patent on GLARE was filed in October 1987 by AKZO. ${ }^{6,7}$ During the years 1992 to 1997, Vlot performed many tests, such as quasi-static test, low velocity and high velocity impact on a wide range of FML samples, and concluded that the FMLs had a much higher resistance than aluminum and composite layers against impact. ${ }^{8-10}$ Also, Vlot by comparing the FML types (ARALL, CARALL and GLARE) found that GLARE can absorb more energy and has less deformation. ${ }^{9}$

After Vlot, considerable researches were performed on the behavior of FMLs as well as optimization of FML specimens. The effect of lay-up configuration of the FML panels has been investigated by many researchers. ${ }^{1-15}$ For example, studies showed that the cross-ply configuration had a higher energy absorption than the unidirectional fiber lay-up. ${ }^{11,12}$ By investigating the effect of materials, at the University of Delft, studies on aramid fiber with aluminum layers indicated that using the 7475 aluminum alloy led to high strength but relatively poor fatigue properties, and ARALL with 2024 type had a lower strength but superior fatigue properties. ${ }^{7}$ In addition, later works have shown that with usage of 2024 aluminum alloy in the production of samples, FML will require more energy to fail. ${ }^{11,16}$ Similar to those studies, Sharma and $\mathrm{Khan}^{17}$ investigated the effect of the distribution of aluminum layer through the thickness of FMLs and indicated that the lateral spread of damage within the FML can be decreased by distributing the aluminum layers in the FML. By examining indenter 
geometry, Cantwell et al. ${ }^{18}$ concluded that flat indenters made less plastic deformation in FMLs than the hemispherical types.

Introducing reinforcing phases into the matrix of composites is a method of improving the mechanical behavior of polymeric composites. ${ }^{19}$ The effect of using nanofiller-modified matrix in manufacturing of FMLs has been investigated by many researchers. ${ }^{19-27}$ Megahed et al. ${ }^{20}$ studied the mechanical properties of GLARE by adding several types of nanofillers such as aluminum (Al), copper $(\mathrm{Cu})$, titanium oxide $\left(\mathrm{TiO}_{2}\right)$, silica $\left(\mathrm{SiO}_{2}\right)$, aluminum oxide $\left(\mathrm{Al}_{2} \mathrm{O}_{3}\right)$ and nano clay $(\mathrm{NC})$. They reported that adding $\mathrm{SiO}_{2}$ nanoparticles into the composite laminates of GLARE caused a maximum improvement of $39 \%, 33.2 \%$ and $108.4 \%$ in tensile strength, modulus and toughness as compared to the unreinforced Glare. Zhang et al. ${ }^{22}$ and Khoramishad et al. ${ }^{19}$ studied the effect of adding multi-walled carbon nanotubes (MWCNTs) on impact behavior of the FMLs and stated that the incorporation of MWCNTs can improve the impact resistance of specimens.

In recent years, evaluating the mechanical properties of graphene-based composites has become popular in both academia and industry. ${ }^{28}$ The GNPs, as one of the most widely used nanoplatelets, have been able to enhance the properties and strength of composite specimens. ${ }^{29-35}$ Significant improvements in strength, fracture toughness, and fatigue strength have been reported using graphene as fillers or reinforcements in nanocomposites.$^{36}$ Domun et al. ${ }^{32}$ incorporated GNPs at concentrations of $0.1,0.25,0.5,0.75$ and $1 \mathrm{wt} \%$ into epoxy resin and stated that maximum stiffness and fracture toughness at $0.25 \mathrm{wt} \%$ were increased by $5.6 \%$ and $51.2 \%$, respectively. Similar to this research, Liaghat et al. ${ }^{37}$ prepared nanocomposite specimens with $0.1,0.2$ and $0.4 \mathrm{wt} \%$ GNPs and compared the mechanical properties of those specimens with neat epoxy. They indicated that adding $0.2 \mathrm{wt} \%$ of GNPs increased $42 \%, 32.5 \%$ and $16.8 \%$ ultimate tensile strength, young's modulus and compressive strength, respectively. Moreover, Abbandanak et al. ${ }^{34}$ reported incorporation of GNPs improved flexural and Charpy impact properties of FMLs.

Although the addition of nanofillers to FMLs can enhance the mechanical properties and increase damage resistance, studies on the effect of incorporating nanofillers to FMLs is limited. ${ }^{20}$ On the other hand, in spite of many works focused on the adding GNPs to the epoxy resin and glass fiber composite, to the best of the authors' knowledge, there are very few published studies about incorporating GNPs to FMLs. The current study aims to investigate the quasi-static behavior of composite and FML panels modified by GNPs. The GNPs with a concentration of $0.2 \mathrm{wt} \%$ were added directly to the epoxy resin. The modified epoxy was applied using a hand lay-up method to the composite and FML specimens. The specimens then tested under indentation and punch loading to 
evaluate the quasi-static behavior of fabricated panels. Mechanical parameters such as peak load, maximum deflection (occurred in the peak load), absorbed energy and specific energy absorption (SEA) were considered for a close investigation.

\section{Experimental procedures}

\subsection{Materials}

The FML panels were made of AL 2024-T3 alloy with a thickness of $0.5 \mathrm{~mm}$ per layer and a composite laminate. The composite laminate was made of woven glass fibers, epoxy resin and graphene nanoplatelets. More details of the materials used in this study have been reported in Table 1.

Table 1. Type and mechanical properties of materials.

\begin{tabular}{ccc}
\hline Material & Type & Material properties \\
\hline Aluminum & $2024-\mathrm{T} 3$ & $\mathrm{E}=72 \mathrm{GPa}, \rho=2700 \mathrm{~kg} / \mathrm{m}^{3}, v=0.3$ \\
E-Glass Fiber & Plain Woven & $\rho_{\mathrm{A}}=400 \mathrm{~g} / \mathrm{m}^{2}$ \\
Epoxy System & ML-506 (HA-11 hardener) & $\rho=1.1 \mathrm{~g} / \mathrm{cm}^{3}$, Curing Temp. $=$ Room Temp. (cold-cured), \\
Gel Time $=24 \mathrm{~min}$, Time to Max. Strength $=7$ days \\
Graphene Nanoplatelets & XG Science Grade C & $\rho=2.2 \mathrm{~g} / \mathrm{cm}^{3}, \mathrm{SSA}=750 \mathrm{~m}^{2} / \mathrm{g}$ \\
\hline
\end{tabular}

\subsection{Dispersion of GNPs into epoxy resin}

Aforementioned, Liaghat et al. ${ }^{37}$ incorporated GNPs at concentrations of 0.1, 0.2 and 0.4 wt $\%$ into epoxy resin and claimed that epoxy with $0.2 \mathrm{wt} \%$ of GNPs had a superior mechanical properties compare to other combinations as shown in Figure 1. According to these observations, the incorporation of $0.2 \mathrm{wt} \%$ GNPs was used in the present study to modify the epoxy resin.

The GNPs were added into epoxy, without using of solvent and mixed by a high shear-mixer. To do this, firstly, the shear-mixer was used for $20 \mathrm{~min}$ at $2000 \mathrm{rpm}$. Secondly, for better dispersion and exfoliation and preventing agglomeration of GNPs, a tip ultrasonicator (UPS400S, Hielscher, Germany) at amplitude $=70 \%$ was used for $13 \mathrm{~min}$. Then, the shear-mixer was used once again for $15 \mathrm{~min}$ at $500 \mathrm{rpm}$. Finally, to remove voids (air bubbles) created in the resin during mixing process, the mixture degassed for 15 min under vacuum (WOV-30 Precise Vacuum Oven, WiseVen, South Korea). This modified epoxy was used in fabrication of modified specimens. It should be noted that all these processes were done at room temperature. 


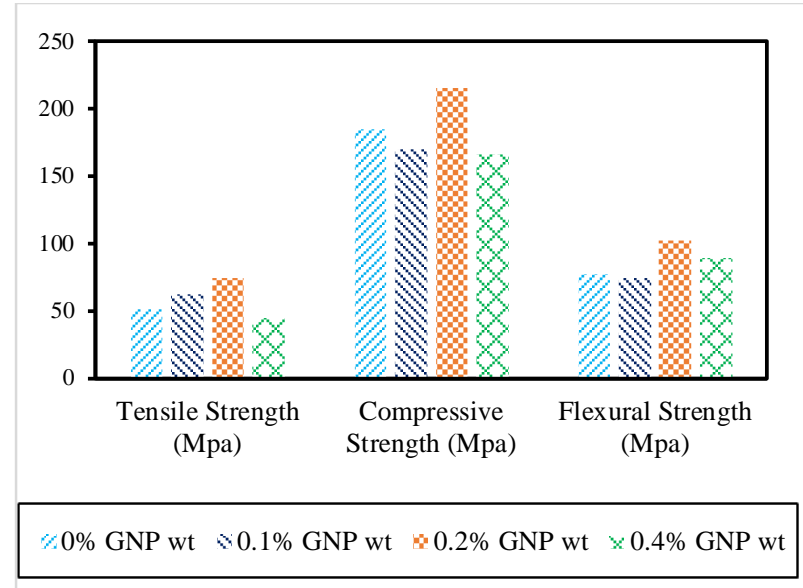

(a)

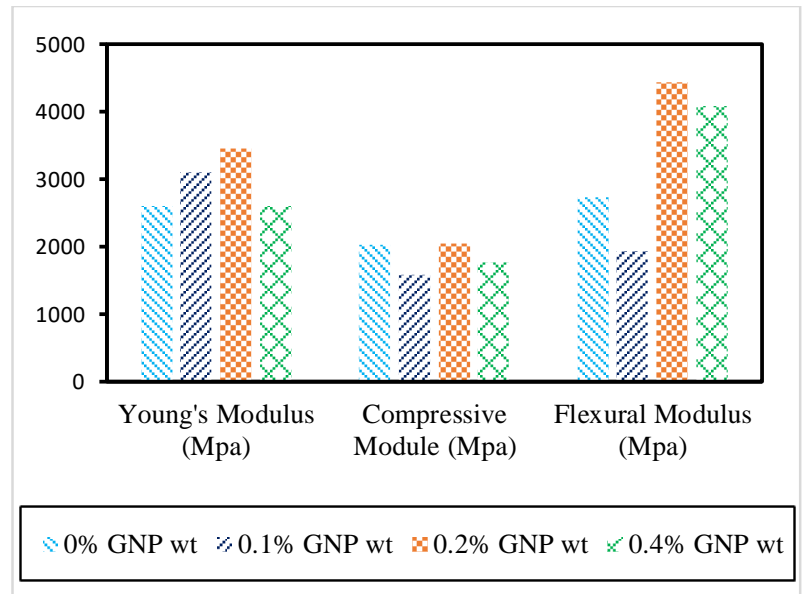

(b)

Figure 1. The mechanical behavior comparison of epoxy resin with different percentages of GNPs in tensile, compressive and flexural tests: (a) comparison of strength; (b) comparison of modulus. ${ }^{37}$

\subsection{Fabrication and specimen preparation}

The unmodified and modified composite and FML panels were manufactured in order to investigate the effect of adding of $0.2 \mathrm{wt} \%$ on quasi-static behavior of panels. The specimens were manufactured by hand lay-up method and FMLs were fabricated with two sheets of aluminum and a composite laminate. The composite laminate was made of eight layers of glass/epoxy. Schematics of the FMLs fabrication are shown in Figure 2. As indicated, in the FML specimens, the stacking sequence is $\left[\mathrm{AL} / \mathrm{GE}_{8} / \mathrm{AL}\right]$ and it is noteworthy that the lay-up configuration of composite specimens is the same as the composite laminate $\left(\left[\mathrm{GE}_{8}\right]\right)$ in the FMLs.

Before fabrication of FML panels, the surfaces of aluminum sheets were pretreated according to the ASTM D2651 protocol to improve bonding between the aluminum and composite laminate. The sheets were washed with acetone and degreased using an alkaline solution, and then abraded using a nonmetallic abrasive paper. The abrasive particles bonded to the paper had a particle-size of 180 $\mu \mathrm{m} .{ }^{38}$ Afterwards abrasive particles and debris were rinsed from the surface by warm-to-hot water. Finally, the sheets left at ambient conditioning for about one hour before applying the adhesive. At the weight ratio of 100:13, resin and hardener were mixed. To eliminate voids, the mixture was degassed for 5 min under vacuum. After hand lay-up process, the specimens were pressed under 1.5 bar pressure. ${ }^{6}$ The preparation of specimens was performed at room temperature and the dimensions of the manufactured panels were $12.5 \mathrm{~cm} \times 12.5 \mathrm{~cm}$. 


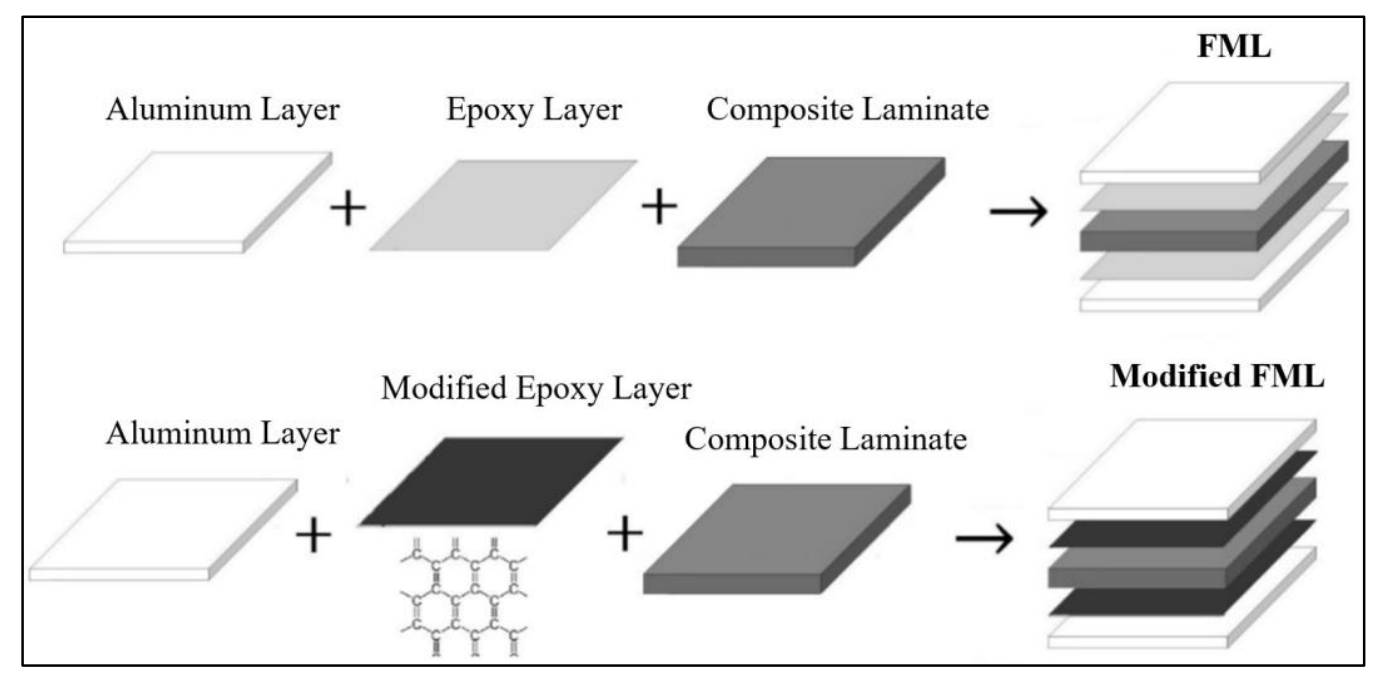

Figure 2. Schematics of modified and unmodified FMLs fabrication.

\subsection{Testing procedure}

Quasi-static punch and indentation loading were performed on both unmodified and modified composite and FML panels. For a clear comparison, in addition to these specimens, AL sheets were also tested under indentation loading. Tests were repeated five times for each two types of loading. In Table 2, stacking sequences and specifications of the specimens are listed.

Table 2. Stacking sequences and specifications of panels.

\begin{tabular}{|c|c|c|c|c|}
\hline Test & Specimens & Stacking Sequence & Mass (g) & Thickness (mm) \\
\hline \multirow{4}{*}{$\begin{array}{c}\text { Quasi-Static } \\
\text { Punch }\end{array}$} & Composite without GNPs & {$\left[\mathrm{GE}_{8}\right]$} & $39.68 \pm 0.35$ & $1.54 \pm 0.11$ \\
\hline & Composite with GNPs & {$\left[\mathrm{GE}_{8}\right]$} & $39.36 \pm 0.50$ & $1.52 \pm 0.08$ \\
\hline & FML without GNPs & {$\left[\mathrm{AL} / \mathrm{GE}_{8} / \mathrm{AL}\right]$} & $92.90 \pm 1.95$ & $2.68 \pm 0.23$ \\
\hline & FML with GNPs & {$\left[\mathrm{AL} / \mathrm{GE}_{8} / \mathrm{AL}\right]$} & $89.05 \pm 1.07$ & $2.57 \pm 0.10$ \\
\hline \multirow{6}{*}{$\begin{array}{l}\text { Quasi-Static } \\
\text { Indentation }\end{array}$} & Single-layer AL & {$[\mathrm{AL}]$} & 21.22 & 0.50 \\
\hline & Double-layer AL & [AL/Air Gap/AL] & 42.41 & 2.75 \\
\hline & Composite without GNPs & {$\left[\mathrm{GE}_{8}\right]$} & $39.93 \pm 0.23$ & $1.52 \pm 0.08$ \\
\hline & Composite with GNPs & {$\left[\mathrm{GE}_{8}\right]$} & $38.12 \pm 0.40$ & $1.47 \pm 0.10$ \\
\hline & FML without GNPs & {$\left[\mathrm{AL} / \mathrm{GE}_{8} / \mathrm{AL}\right]$} & $93.19 \pm 1.65$ & $2.85 \pm 0.19$ \\
\hline & FML with GNPs & {$\left[\mathrm{AL} / \mathrm{GE}_{8} / \mathrm{AL}\right]$} & $90.57 \pm 1.37$ & $2.65 \pm 0.21$ \\
\hline
\end{tabular}

* Dimensions of all specimens are $12.5 \mathrm{~cm} \times 12.5 \mathrm{~cm}$.

** GE represents Glass-Epoxy layer.

Panels were clamped in a circular fixture with a diameter of $15 \mathrm{~mm}$ in the punch test and a square fixture with internal dimensions of $10 \mathrm{~cm} \times 10 \mathrm{~cm}$ in the indentation test. As demonstrated in Figure 3, loading in both tests was applied using a Universal Testing Machine (Model: WDW-300E). The indenter that used in both tests was flat-ended cylinder with $10 \mathrm{~mm}$ diameter and its loading rate was $5 \mathrm{~mm} / \mathrm{min}$. The loading was continued until a full perforation achieved. 


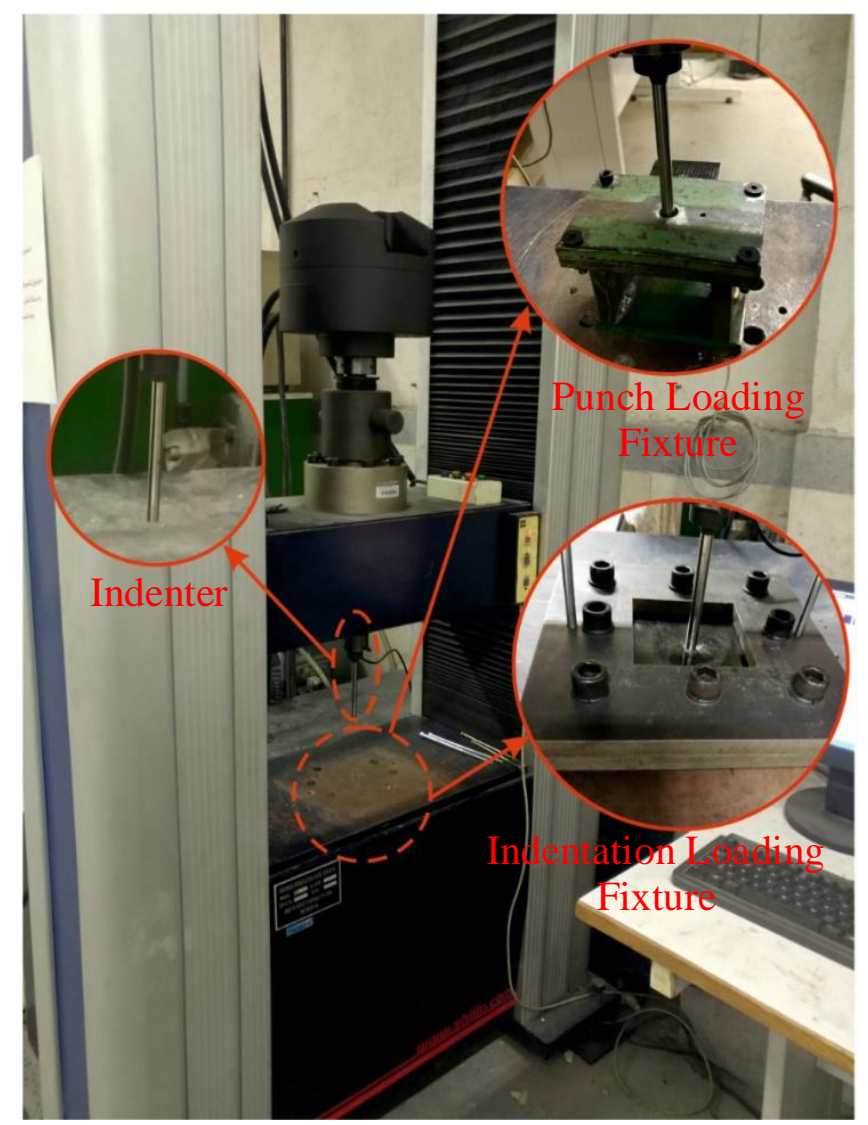

Figure 3. Fixture installation on Universal Testing Machine.

\section{Results and discussion}

\subsection{Quasi-static punch loading}

To investigate the effect of GNPs combination in the composite and FML panels, the results of quasistatic punching are presented, and discussed in the following sections.

\subsubsection{Composite panels}

The load-displacement curves of the punched composite specimens (with and without GNPs) are demonstrated in Figure 4 and Figure 5. A close look at the load-displacement curves shows that the overall shape of curves follows a similar pattern and this means that the failure modes are similar. However, the failure modes have been delayed by adding the GNPs and this leads to higher fracture toughness in specimen with GNPs. The results also showed that the inclusion of GNPs into the composite specimen increased the maximum load by $8.2 \%$ and the deflection by $14.7 \%$. Consequently, an enhancement of $19.3 \%$ for energy absorption and $20.3 \%$ for SEA were achieved. The SEA was calculated from following equation. 


$$
S E A=\frac{E(\text { absorbed energy })}{m_{s}(\text { mass of specimen })}
$$

The load-displacement curves have been classified into five zones as shown in Figure 5. The mechanical behavior of the specimens against the punch test, the failure modes and damage mechanisms in each zone are discussed below.

In both curves, at point $\mathrm{A}$, the indenter lands on the panel, then by moving the indenter, in the region of A-B, the membrane stretching is applied. Since the behavior of the composite panels is linear elastic, no failure has occurred. The behavior of the two curves from the start of loading (point A) to point $\mathrm{B}$ is similar.

At point B, the slope of the graphs suddenly decreases, this indicates that the damage mechanisms in the $\mathrm{B}-\mathrm{C}$ area differ from the $\mathrm{A}-\mathrm{B}$ area. In the $\mathrm{B}-\mathrm{C}$ region, the behavior of the samples is nonlinear, and the panels enter the plastic region. In this region, micro-cracks, and pre-delamination in the glass/epoxy layers have occurred and reduced the slope of the load-displacement curves. This reduction in reinforced composite panel is slightly greater than that in unreinforced one. This is mainly due to the more brittleness of modified epoxy, which causes further damage to modified panel. In addition to membrane stretching, some failure modes such as out of plane stretching, out of plane crushing, bending moment and shear force are also applied and the major strength of specimens is observed in this region.

At point $\mathrm{C}$, the compressive load of the indenter reaches its maximum value. In addition, at this point, since in specimen with GNPs, there is a strong bonding between polymer chains (in the resin) and graphene nanoplatelets, the peak load and the maximum deflection in this specimen are more than unmodified specimen. When the load reaches the maximum value, failure in the specimens starts and the initiated shear crack propagates to form a petal from point $\mathrm{C}$ to $\mathrm{D}$. The created petal (Figure 4) becomes completed at point $\mathrm{D}$ where the indenter fully perforates in the panels. It is noteworthy that shear mode is the dominant failure mode in C-D region. As the indenter passes through the specimens, the strength of the panels is decreased and as a result, the load suddenly drops to point E. It is found that, by moving the indenter through the specimens in the E-F region, the bending of formed petal and stick-slip frictional motion between indenter and specimens lead to energy dissipation. Since the modified composite has a higher strength, the absorbed energy of this specimen in E-F region is greater as compared to that of unmodified one. 

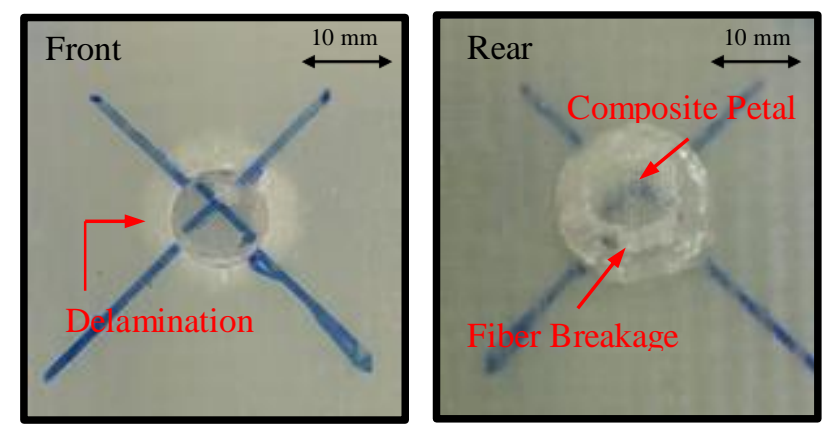

(a)
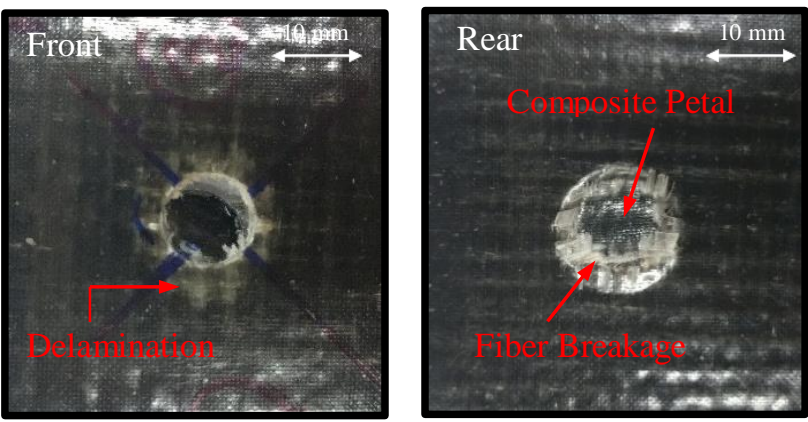

(b)

Figure 4. Quasi-static punch damages in composite: (a) unmodified panel; (b) modified panel.

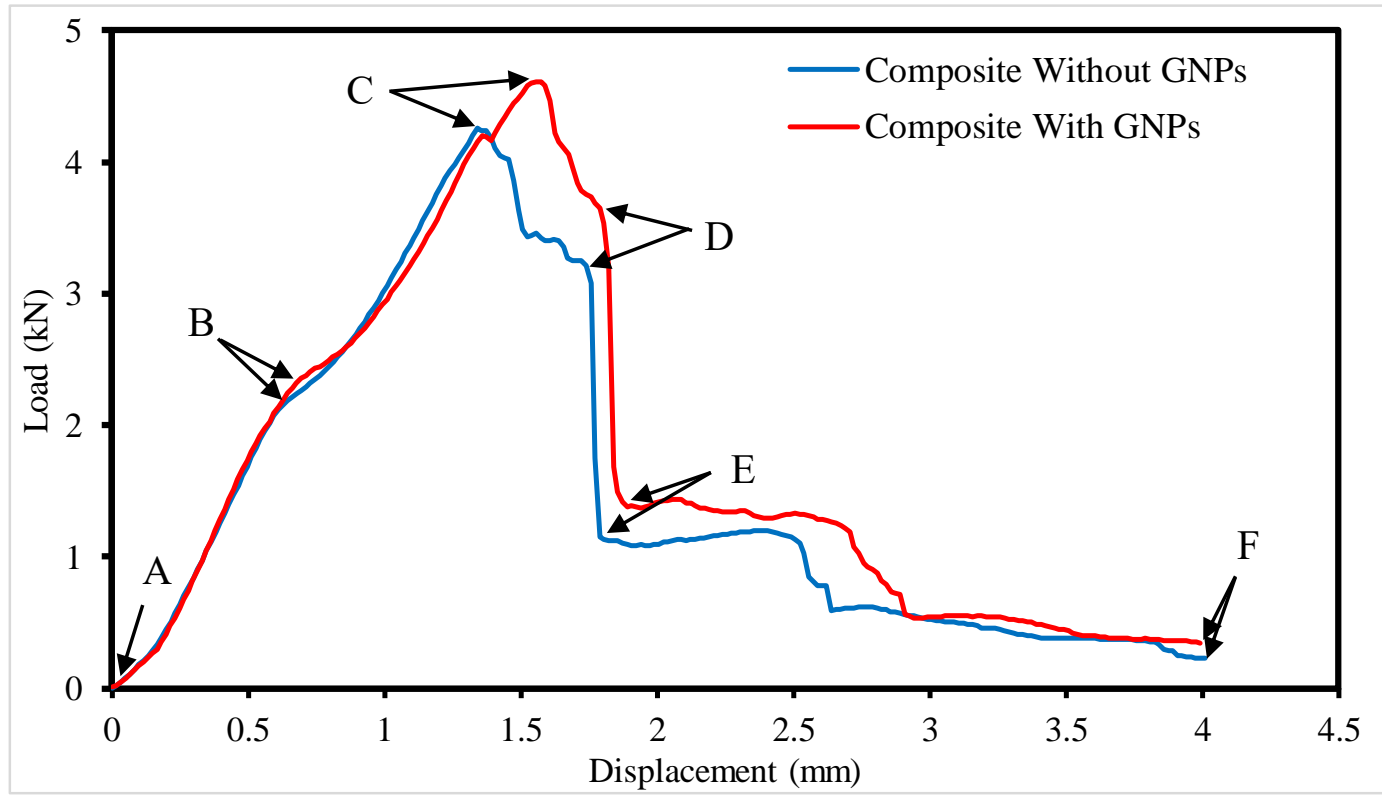

Figure 5. The load-displacement curves of composite panels under punch test.

\subsubsection{FML panels}

Figure 7 illustrates the load-displacement curves of the unmodified and modified FML panels. It is found that, the overall pattern of the curves is similar, it means that two panels had the same failure 
modes, but by addition of GNPs, all the failure modes have been delayed. This delay leads to more fracture toughness and strength in modified specimen.
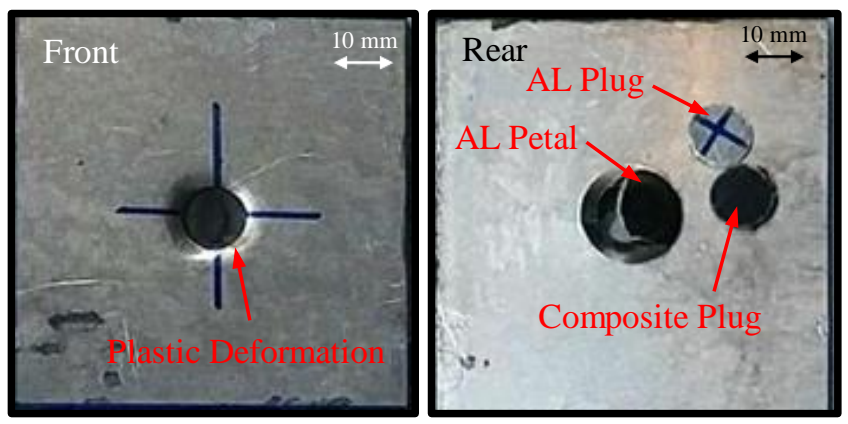

Figure 6. Quasi-static punch damages in modified FML.

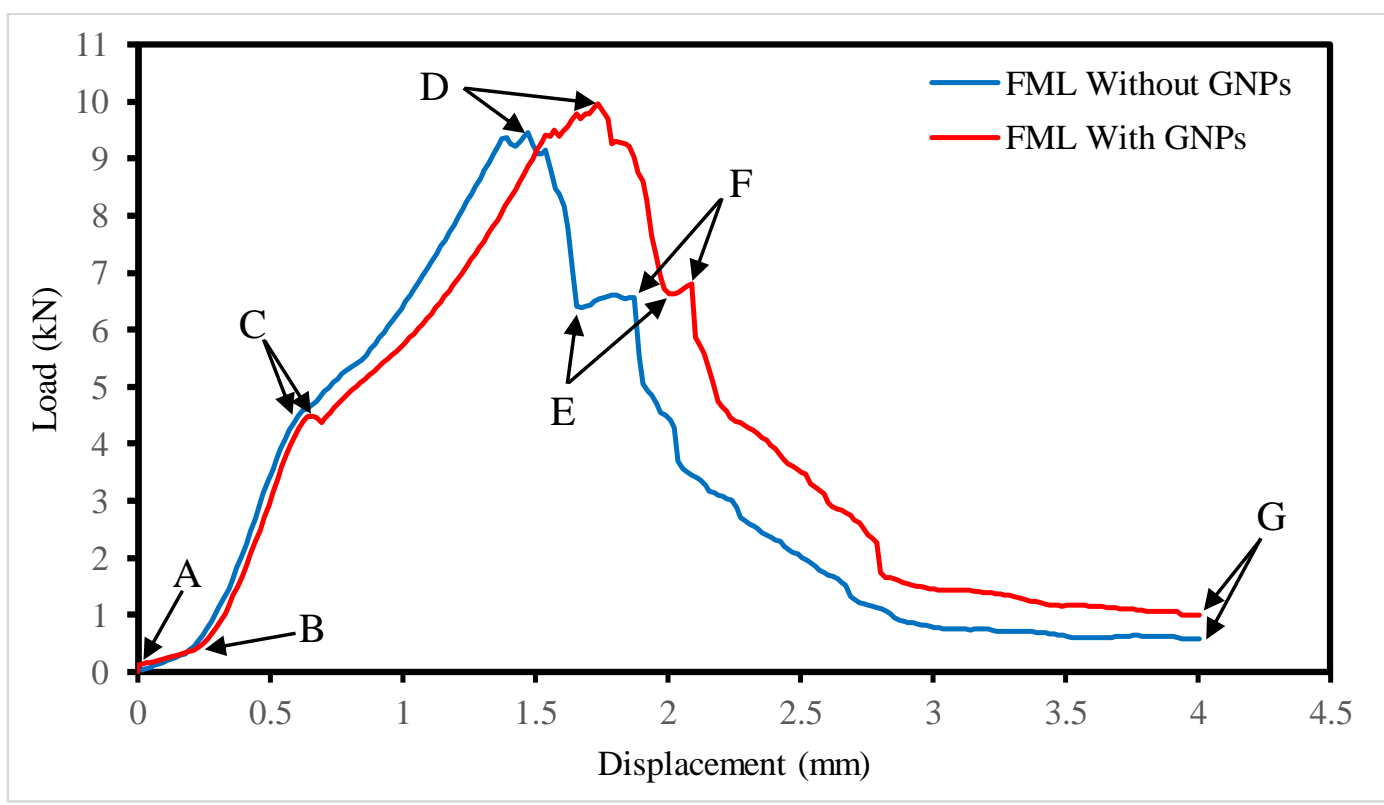

Figure 7. The load-displacement curves of FML panels under punch test.

Hence, for the reinforced specimen, the peak load, maximum deflection, energy absorption and SEA were increased by $10.1 \%, 16.0 \%, 24.9 \%$ and $31.7 \%$, respectively in comparison with unreinforced specimen. During the loading stage, when the indenter perforates in FML specimens, a shear plug with a diameter equal to the indenter is formed in upper AL layer. And then, the separated plug and indenter move along the specimens. Consequently, the plug is created in the composite laminate and a petal is formed in lower AL layer. These plugs and petal have been created as a result of combined bending moments and shear forces which have been applied to the specimens during the loading process. As seen in Figure 7, the load-displacement curve of the modified FML includes three peaks, 
while, the unmodified curve has two peaks. These curves are divided into six sections and the behavior of specimens, failure modes and damage mechanisms will be discussed in each section.

The A-B region illustrates the indenter establishment on the panels. While, in the B-C region, by moving the indenter, the membrane stretching is applied and the behavior of the FML panels is linearelastic. Also, the observations during the test indicated that no failure occurred in this region. At point $\mathrm{C}$, the slope of the curves suddenly decreases. This indicates that, the behavior of FMLs in the C-D section is different from the B-C. In modified FML in addition to reduction of slope, a slight drop in the amount of load is also observed at point $\mathrm{C}$. The curve hits its first peak in this point due to the debonding between the AL layer and composite laminate of FML. This local debonding has occurred, since by addition of GNPs, the adhesive bonding between these two layers has become more brittle. In the C-D section, the curves show that the behavior of specimens is nonlinear. By moving the indenter, localized plastic deformation in the AL layers and micro-cracks and pre-delamination in the composite laminate have occurred. It should be noted that, noises that were produced during the test confirm the mentioned damages. Also, the major strength of specimens is observed in C-D region and the failure modes include membrane stretching, out of plane stretching, out of plane crushing, bending moment and shear force.

According to Figure 8, it can be concluded that the overall shape of the FML and composite curves is similar. It means that, in B'-D' region, the curves consist of two parts with two different slopes. Therefore, the main reason for slope reduction in the FML curves (point $C^{\prime}$ ) is the behavior of the composite laminate in FML panels. It is worth noting that, the improvement of the FML properties compared to the composite specimens can be achieved by adding aluminum layers, increasing the panel thickness and the interaction effect between aluminum and composite laminate.

At point D in Figure 7, the applied load reaches its maximum value and a plug is created in the upper AL layer due to the localized plastic deformation. Simultaneously, bending moments and shear forces have led to the formation of a plug in the composite laminate, too. The formed plugs can be clearly observed in Figure 6. The fluctuations around point D for the reinforced specimen are ascending, while they occur with nearly zero slope for the unreinforced specimen. These fluctuations represent the formation of the plug and the damages in the composite laminate of FMLs. And also, the ascending fluctuations indicate that the strength of the composite and adhesive layers in reinforced specimen is greater than the unreinforced one. 
It is noteworthy that, incorporation of GNPs in specimens would have dual role. The first role is the enhancement of elasticity modulus and the second role is the increase of strength. In this study, the addition of GNPs has no effect on the modulus of the reinforced FML for two reasons: first, the weight rate of graphene nanoplatelets in the FML compared to that of the aluminum composite is very low (B-C section of Figure 7). Second, since Papageorgiou et al. ${ }^{28}$ have reported, the modulu s of the graphene-based nanocomposite presents a significant percentage increase when the modulus of the host material is low and in this work, the elastic modulus of FML (host material) is very higher than modified resin, no improvement in the elastic modulus of the specimens has been obtained.

Although the modulus of the reinforced FML is not improved, incorporation of GNPs obviously causes the strength and fracture toughness to increase by delaying the failure modes. The ability to improve the strength and fracture toughness of epoxy with incorporation of graphene nanoplatelets has reported in many investigations. ${ }^{28,30,32,37}$

While the plug is formed in the AL layer and the composite laminate fails, the strength of the FML panels is reduced and this reduction is shown in the D-E section of the curves. After perforation of the upper AL and composite laminate, the indenter reaches the lower layer of AL. From this point onwards, the lower AL layer carries the load and this can be seen in the E-F region and a petal (Figure 6) is formed at point F. In addition, after this point, an associated hole occurs by fully perforation of the indenter. It turns out that, in the F-G section, the stick-slip frictional motion between the indenter and FMLs is the main source of energy absorption. By moving the indenter through the FMLs, the motion transitions from sticking to slipping or vice versa and as the perforation hole expands, the frictional part of motion is decreased and slipping becomes dominant. It should be noted that, the energy absorption mechanisms in the F-G region includes three parts: removing the plugs of the upper $\mathrm{AL}$ and composite laminate through the perforation hole, bending of the petal that was formed in lower AL layer and stick-slip motion between the specimen and the indenter. 


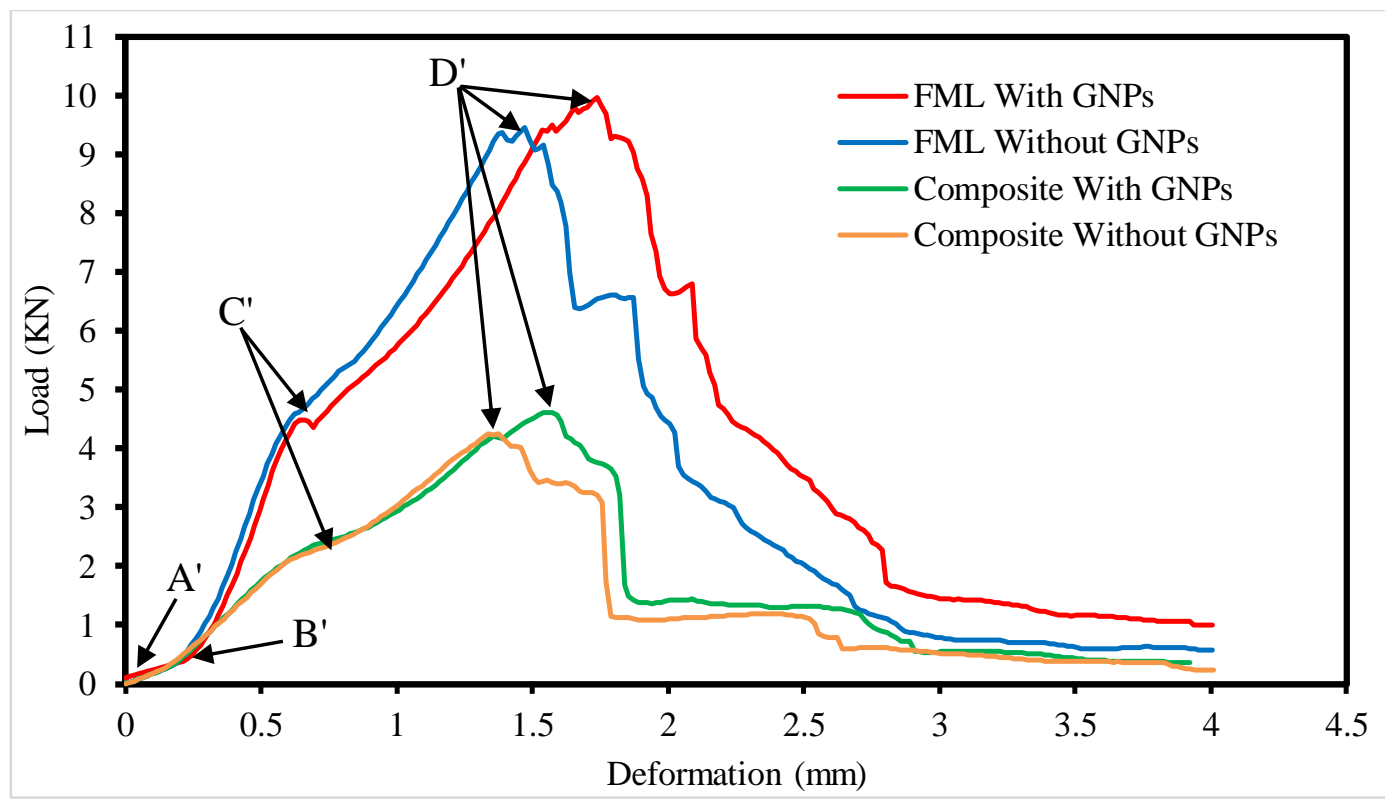

Figure 8. The load-displacement curves of the composite and FML panels under punch test.

The upper fuselage and leading-edges of Airbus A380 aircraft were built with the FML. ${ }^{39}$ On the other hand, the airframe of any flying vehicle comprises structural members that join by riveted lap joints. ${ }^{40}$ It can be said that during riveting process, the structural members are subjected to punch loading. Since the incorporation of GNPs had a positive influence on the behavior of FML panels under punching test, it is recommended to add the GNPs into the composite laminate of FML.

\subsection{Quasi-Static indentation}

As the results showed, the local damage mechanisms appeared under the punch loading, whereas in the indentation test, in addition to the local mechanisms, global mechanisms also occurred. It is worth noting that both tests had the same test conditions, except that the span ratio (the ratio of support span length to indenter diameter) was different for punch and indentation loading which was 1.5 and 10, respectively. In quasi-static indentation test, to get a clear outcome on the damage propagation modes and investigate the interaction effect in the FML panels, aluminum sheets and composite panels were also tested.

\subsubsection{Aluminum sheets}

The quasi-static indentation test was conducted on the single and double aluminum layers and the behavior of these specimens has been analyzed to investigate the interaction effect in FML panels. Figure 9 shows the load-displacement curves of the aluminum specimens and the punched single- 
layer specimen is shown in Figure 11. As can be seen in Figure 10, there is an air gap between the two layers of AL in the double-layer specimen. The gap is equal to the distance between the two layers of AL in the FML (parameter "d" in Figure 10). In other words, in the double-layer specimen, the distance of upper and lower AL layers from the neutral axis is equal to this distance in FML panels.

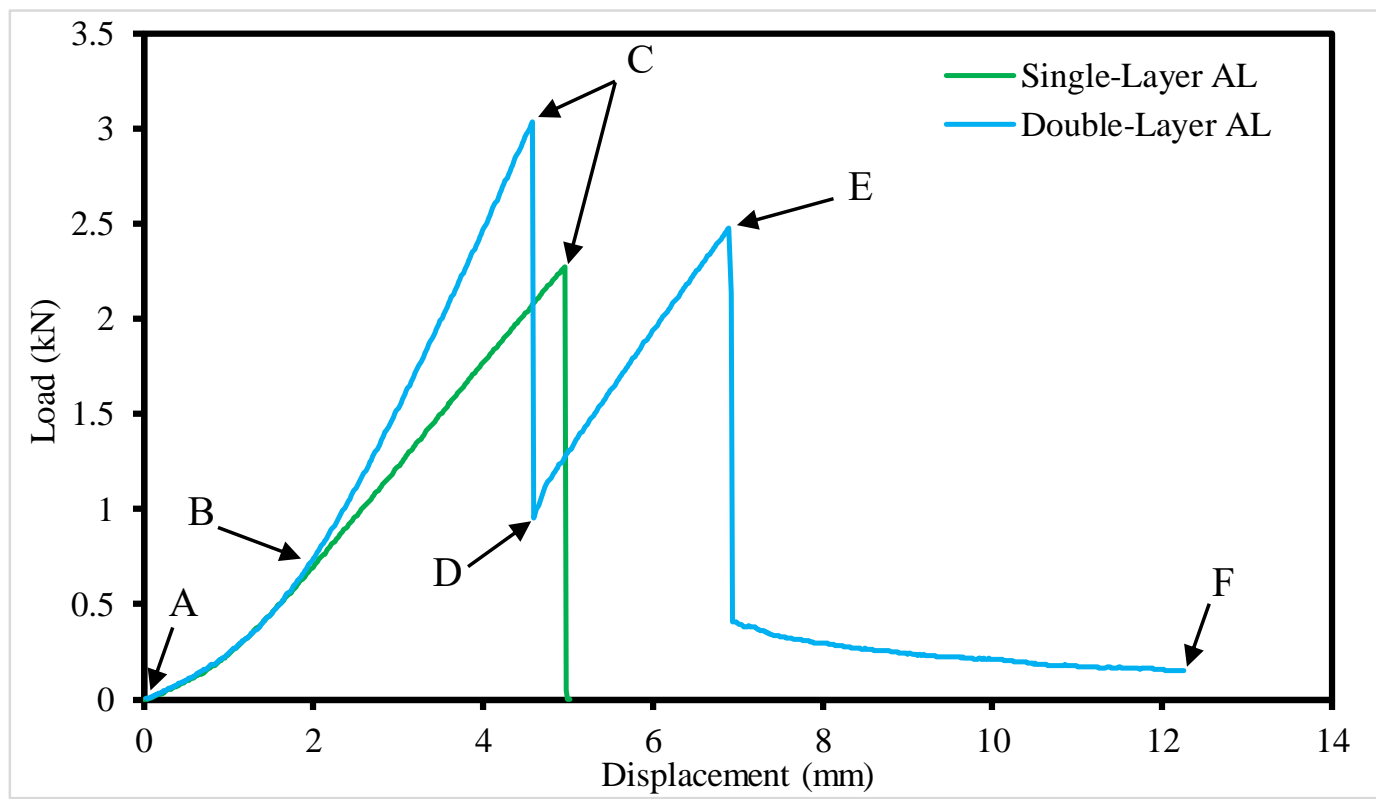

Figure 9. The load-displacement curves of single-layer and double-layer aluminum specimen under quasi-static indentation test.

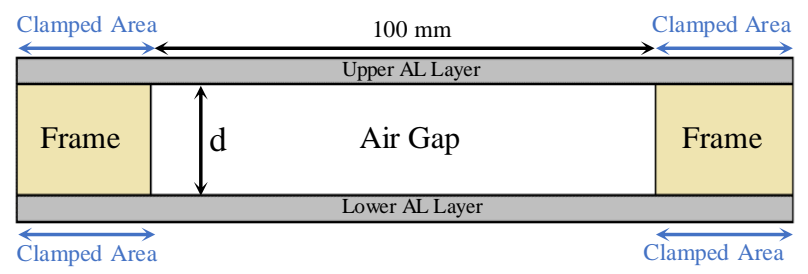

(a)

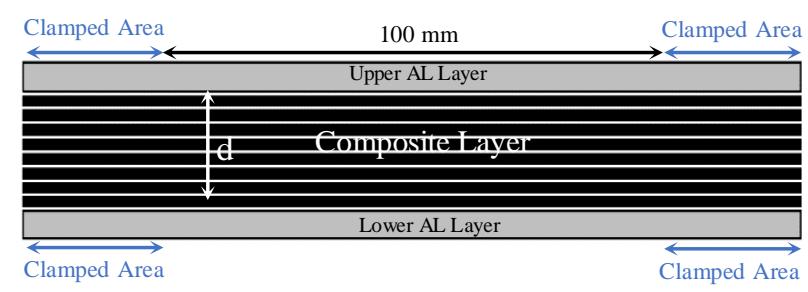

(b)

Figure 10. Schematic lay-up of: (a) the double-layer aluminum specimen; (b) the FML panel.

According to the load-displacement curves, the behavior of the two specimens in A-B section is the same but as the loading increases, this behavior differs in B-C area. The reason is that by moving the 
indenter through the double-layer specimen, the first layer sits on the second layer at point B and the lower layer supports the upper layer, so the strength and elastic modulus have been increased. Since, in the double-layer specimen, the lower layer restricts the displacement of the upper one, the upper layer has less deflection than the single-layer specimen (point C).
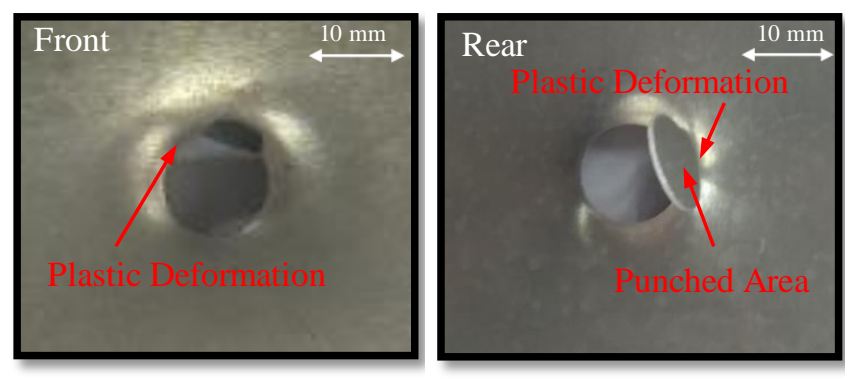

Figure 11. Quasi-static indentation damages in single-layer aluminum.

\subsubsection{Composite panels}

In order to analyze the failure modes and the interaction effect in FML panels, unmodified and modified composite panels were investigated under the quasi-static indentation loading. Figure 12 illustrates the load-displacement curves of the specimens. It is clearly observed that the incorporation of GNPs has affected the behavior of specimen and an improvement of 15.2\%, $12.6 \%, 22.3 \%$ and $31.2 \%$ in peak load, maximum deflection, absorbed energy and SEA were achieved respectively, as compared to the unmodified one.

As shown in Figure 12, the curves are divided into three sections and the behavior of specimens, failure modes and damage mechanisms will be discussed in each reign. The behavior of the two panels is completely identical from point A to B. It is noteworthy that in this region, the applied failure modes are membrane stretching, out of plane stretching, out of plane crushing, bending moment and shear force. It is found that the initial damage mechanisms are localized micro-cracking and micro-delamination. As the load increases, the micro-cracks grow and when the load reaches the maximum amount that the panels can carry (point B), the panels fail. Since, the incorporation of GNPs leads to delay in all the failure damages, the significantly improvement in load carrying capacity and fracture toughness is achieved. At point B, a petal is created in the specimens (see Figure 13) and this is accompanied by the rapid drop of the load in panels. By moving the indenter through the specimens in the C-D region, the bending of formed petal and stick-slip frictional motion between indenter and specimens absorb energy. 
By comparing the behavior of composite panels against punch with that under indentation loading, it can be concluded that the peak loads are in the same order and the damage mechanisms are similar. However, the effect of span ratio leads to a significant increase in the displacement of each damage mode in indentation loading. As an example, the modified composite failure occurs at $7 \mathrm{~mm}$, whereas it takes place at $1.6 \mathrm{~mm}$ in punch test.

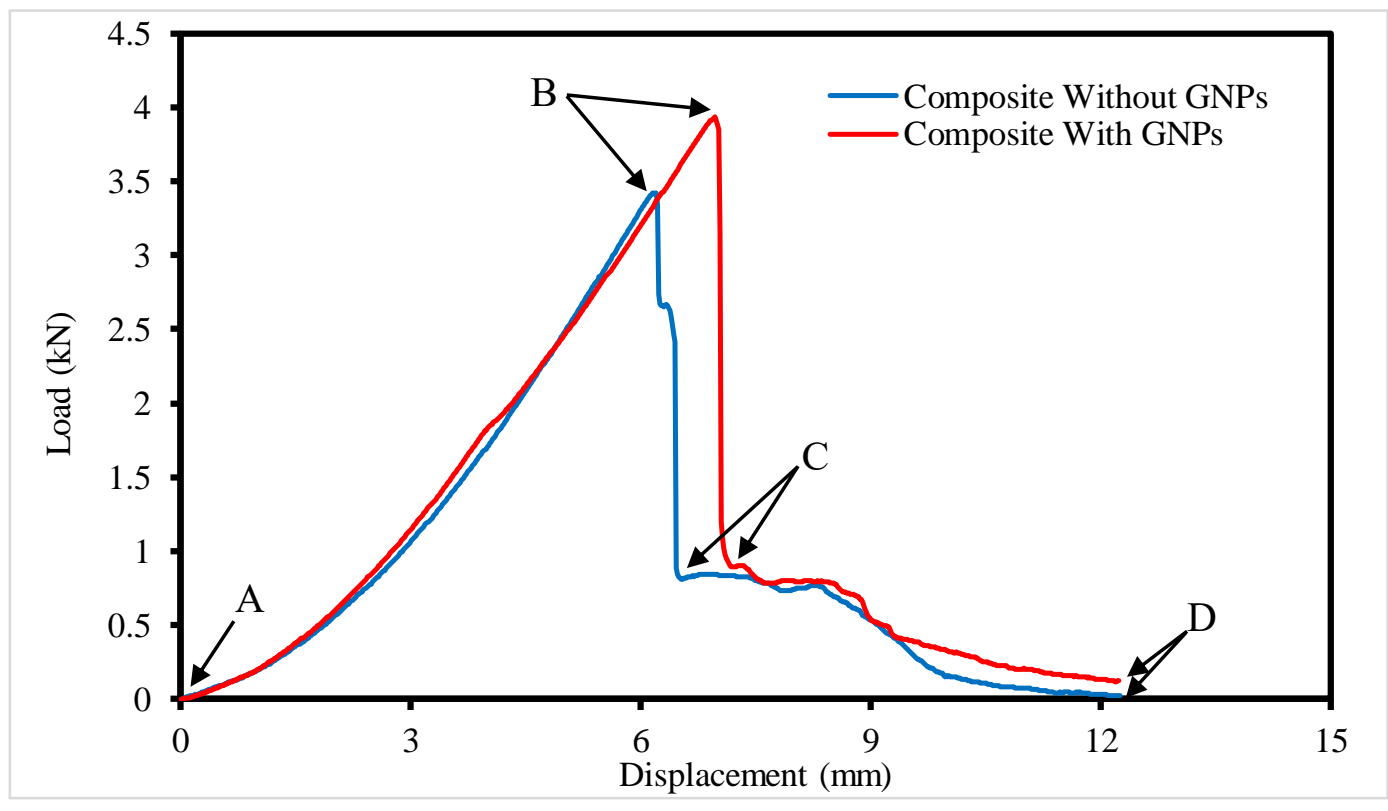

Figure 12. The Load-Displacement curves of composite panels under quasi-static indentation test.
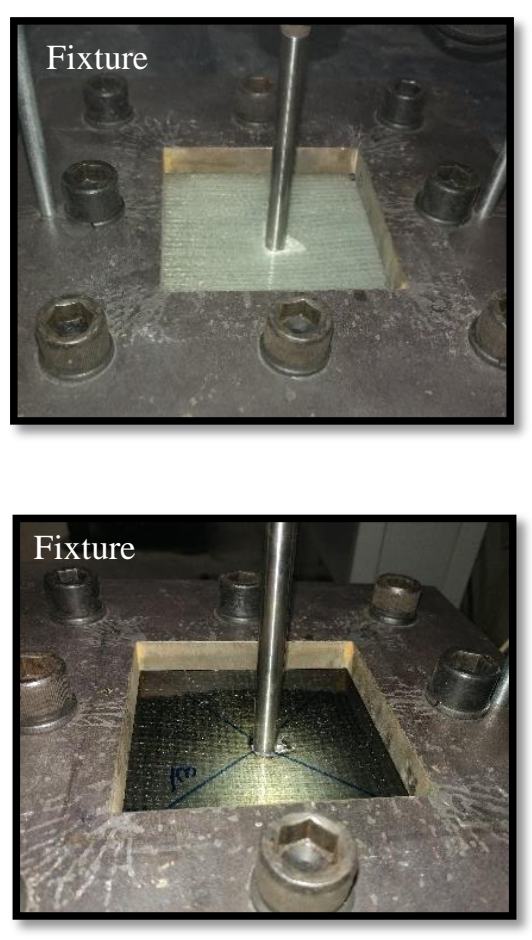

(b)

(a)
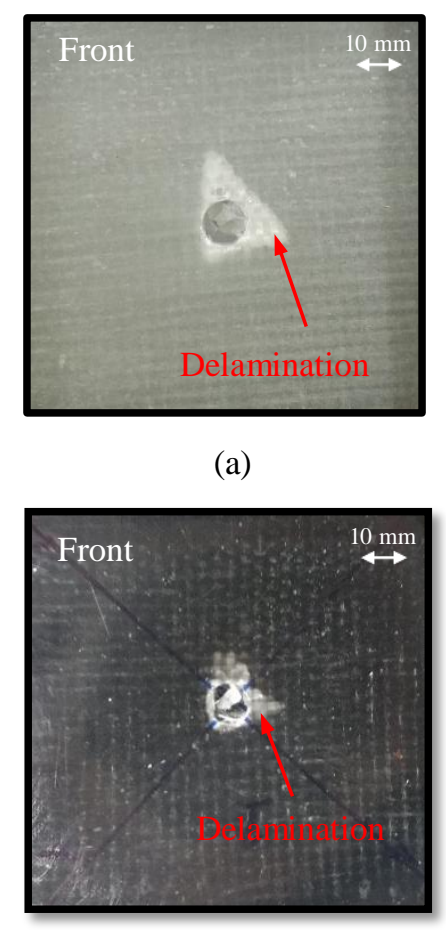
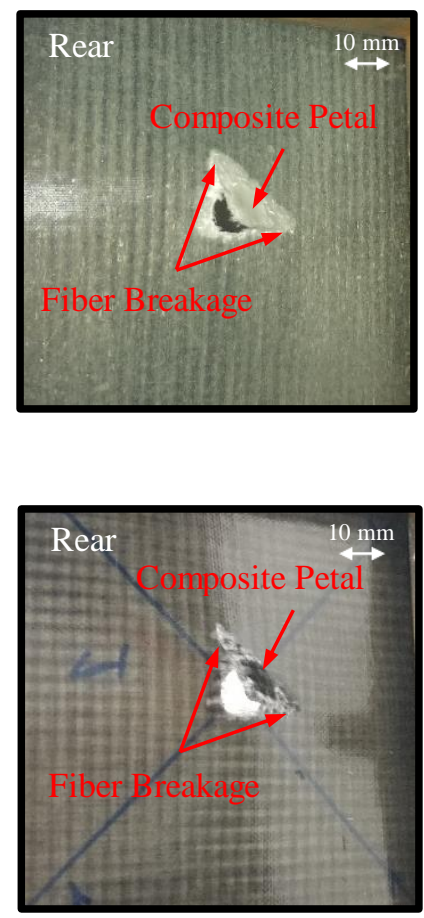

panel; (b) modified panel. 


\subsubsection{FML panels}

The quasi-static indentation loading was performed on the unreinforced and reinforced FML panels, in order to investigate the effects of adding GNPs into the composite layers of FMLs. Figure 14 illustrates the load-displacement curves of the specimens. As seen in this figure, the overall shape of the curves follows a similar pattern, except that there is an extra load-drop indicates by B-C in the modified curve. The results showed that adding $0.2 \mathrm{wt} \%$ of GNPs into the composite laminate of FML caused an improvement of $14.8 \%$ in maximum deflection and a reduction of $6.0 \%$ in peak loa d compared to the unreinforced FML. The load-drop at the first peak in the modified specimen curve has had a negative effect on the second and third peaks and has reduced the amount of load in these peaks. Hence, despite the improvement of maximum displacement, the specific energy absorption and SEA does not change much.

As indicated earlier, for the purpose of examining the interaction effect and damage modes in FML panels, aluminum layers and composite specimens were also tested. In addition, in order to identify the damage assessment within every stage, four FML panels were chosen to be incrementally loaded up to four representative load levels. They indicate by points 1-4 on the load-displacement curve as shown in Figure 16. The panels were cut along the half-section of the damaged region by water-jet device, to observe the propagation of damage modes. The cross-section views of FML panels are given in Figure 17, corresponding to points 1-4 of Figure 16, respectively. Also a similar study was performed by Liang et al. ${ }^{41}$ on composite specimens.

As can be seen in Figure 14, in A-B section, after the establishment of indenter, the penetration load increases linearly up to point B. According to the Figure 17-1, plastic deformation has occurred in $\mathrm{AL}$ layers and the scare of indenter has been left on the upper AL layer (see Figure 16-Point 1). At point $\mathrm{B}$, the load of the modified FML abruptly drops to point $\mathrm{C}$. The behavior of AL and composite specimens (Figure 18), and the cross-sections of FML panels (Figure 16, Figure 17) will also be analyzed to identify the reason behind this load-drop. 


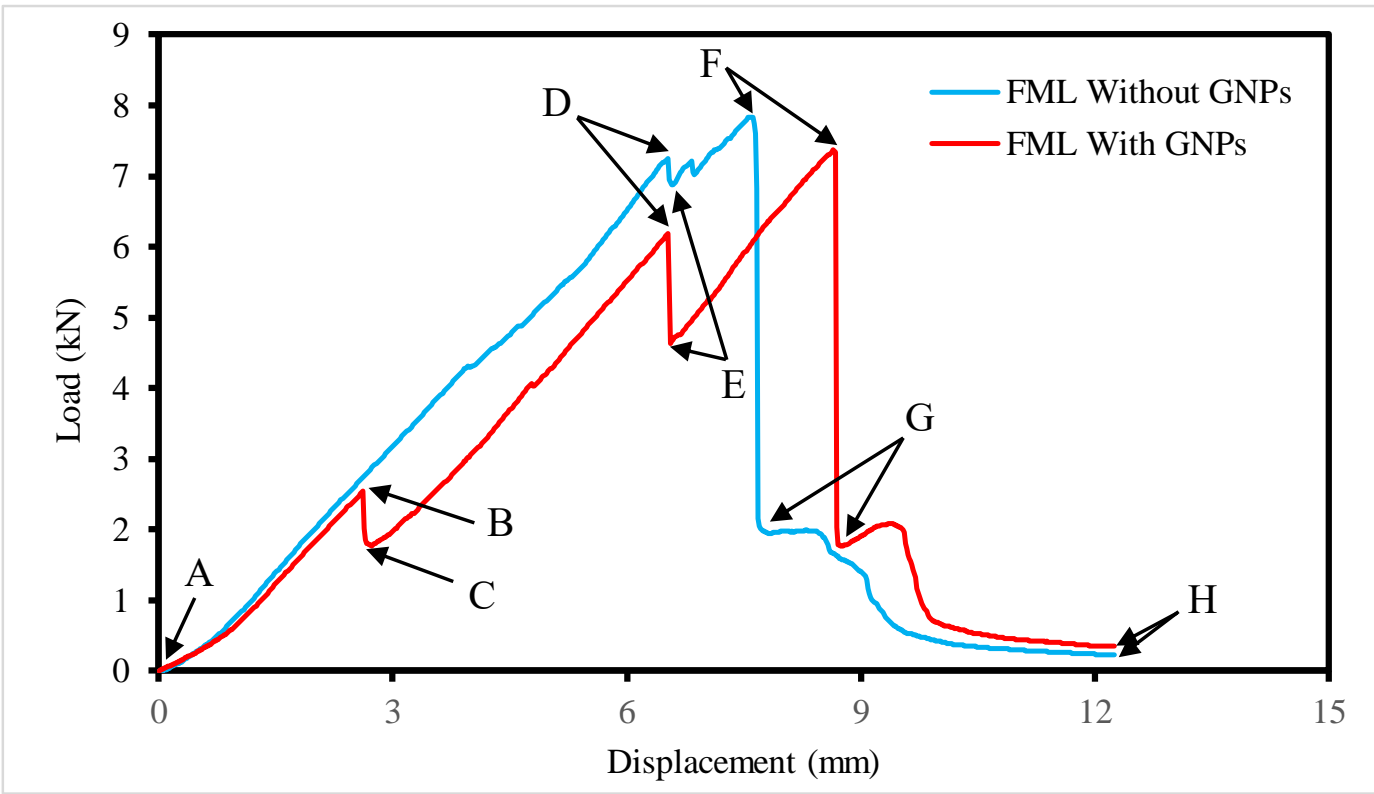

Figure 14. The Load-Displacement curves of FML specimens under quasi-static indentation test.

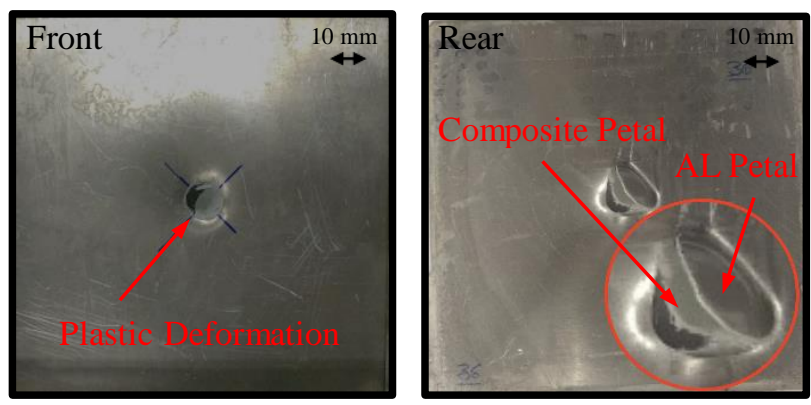

(a)
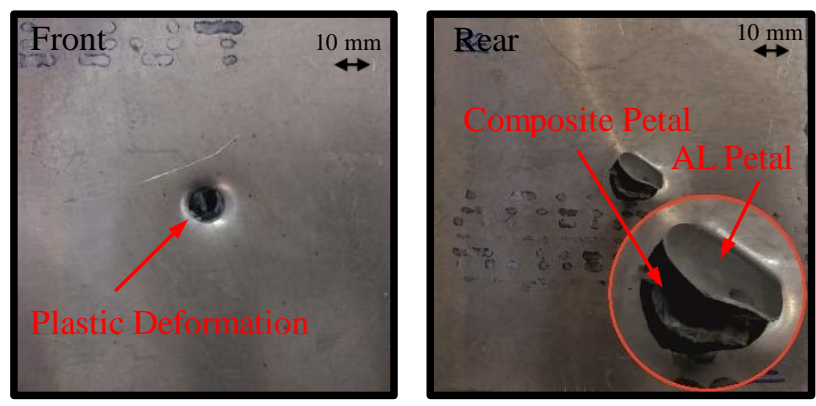

(b)

Figure 15. Quasi-static indentation damages in FML: (a) unmodified panel; (b) modified panel.

As previously mentioned, in the double-layer AL (Figure 18), the lower layer helped to improve the load carrying capacity of the upper layer. Therefore, as expected, in the FML panel, due to the presence of more layers and also the interaction effect between them, the load capacity of AL layer in FML is greater than that in the two-layer AL specimen. Hence, the load-drop at point B is not related to the failure of AL layers. Furthermore, since the load carrying capacity of modified 
composite is about $4 \mathrm{kN}$ (Figure 18) and the load-drop has occurred at $2.6 \mathrm{kN}$ (Figure 14-point B), it can be concluded that this drop is not due to the failure of the composite laminate of FML. By examining the cross-sections, it can be seen that in specimen-1 (Figure 17), an interfacial debonding has occurred between the AL layers and the composite laminate. Therefore, at point B (Figure 14), the debonding causes the sudden load-drop. As previously mentioned in the FML panel under the punch loading, this debonding took place in the modified specimen and no debonding has occurred in unmodified one. It is worth noting that the incorporation of GNPs makes the modified resin more brittle compared to neat epoxy. So, the adding of GNPs has weakened the bonding between the metal/composite interfaces.

In the C-D region, the load fluctuations in the range of 4-6 $\mathrm{kN}$ are an evidence for micro-cracking and micro-delamination in the composite laminate of FML panels and also the sounds were heard during the test confirm these damages. However, according to Figure 17-specimen 2, no significant damage in the composite laminate is observed. As shown by Figure 16, plastic deformation around the penetration point are occurred in aluminum layers and the scare of indenter on the specimen-2 is more obvious than that on the specimen-1. It is noteworthy that, in this region the failure modes are membrane stretching, out of plane stretching, out of plane crushing, bending moment and shear force.

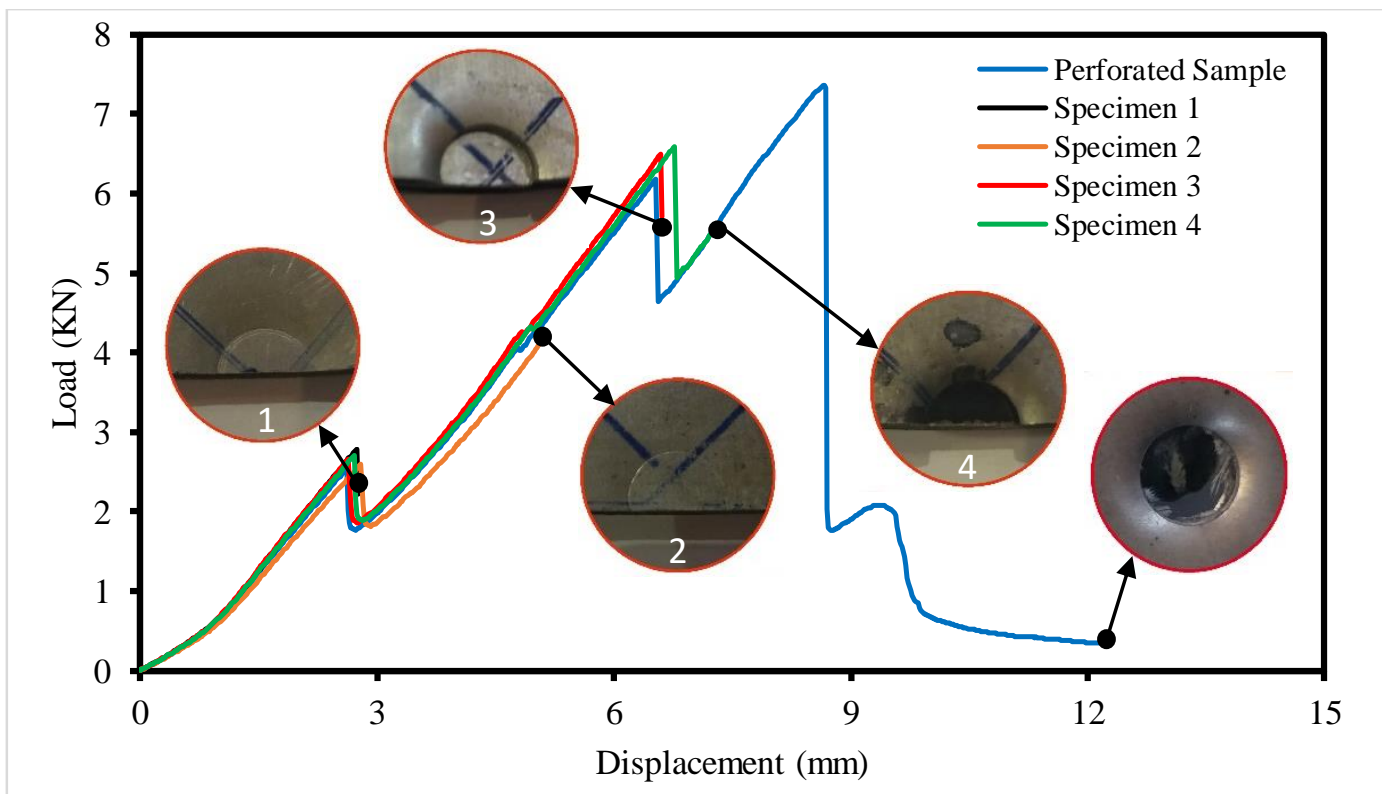

Figure 16. The load-displacement curves of the cross-sectioned FML panels under quasi-static indentation test. 


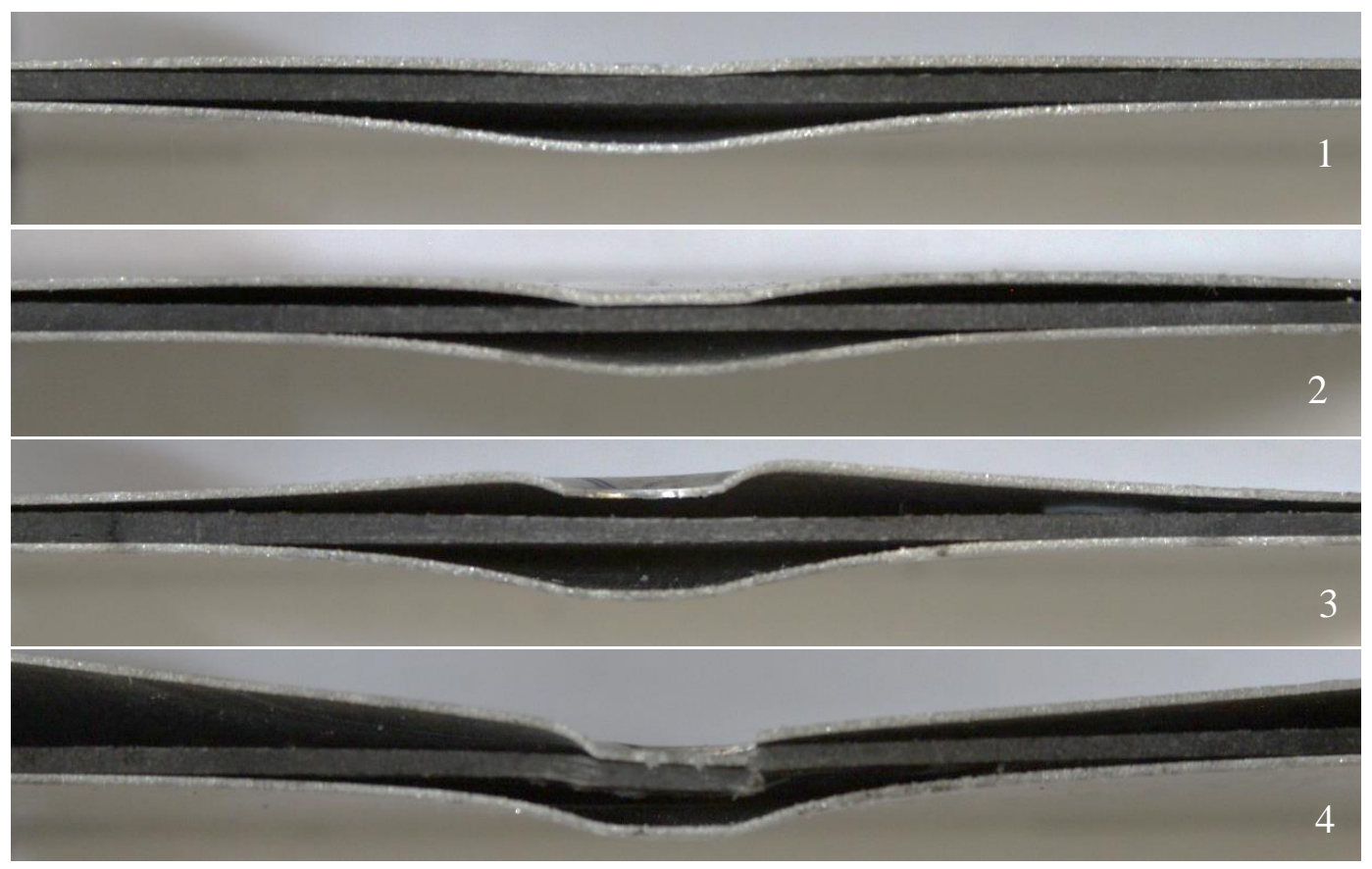

Figure 17. Cross sectional view of FML panels under quasi-static indentation test (indicated by points 1-4 on the Figure 16).

As the load increases toward point D, the damages spread until the load reaches the maximum carrying capacity of upper AL layer. And while the plug formation starts in this layer, the load abruptly drops and the plugging is completed at point E. Also, the plug formation is clearly obvious in Figure 16-specimen 3. Then, in the both specimens, as the upper AL layer fails, the load is carrying by the composite laminate. As can be seen in Figure 14, in the modified specimen, since the upper AL layer is locally separated from the composite laminate, the load has dropped more than unmodified specimen. As observed previously, in the double-layer AL, by entering the indenter to the air gap, the load abruptly dropped. The similarity between the load-drop in modified FML and double-layer AL (as shown in Figure 18) confirms that load-drop in Figure 14-point D is due to the debonding that had occurred at point $\mathrm{B}$. The damage mechanisms in D-E region as can be seen in Figure 17-specimen 3 are the propagation of plastic deformation in the aluminum layers, the debonding between the aluminum and composite laminate and the failure of upper AL layer.

As mentioned earlier and according to Figure 17-specimen 4, when the upper AL layer failed, the load applied to the composite laminate and lower AL layer. Since the composite laminate in the modified panel has more load carrying capacity (see Figure 12), the reinforced FML can carry more load than unreinforced FML in E-F region. It means that the load carrying range of the modified FML is [4.71-7.36] $\mathrm{kN}$ and this range in unmodified one is [6.87-7.82] $\mathrm{kN}$, therefore the modified panel has more than twice load carrying capacity in this region. By moving the indenter in the E-F section, 
the composite laminate and lower AL layer fails through the petalling and due to this the load drops suddenly to point G. The formed petals are visible in Figure 15. The behavior and energy absorption mechanisms of FML specimens in the G-H region (Figure 14) are quite similar to the behavior of FML panels under the quasi-static punch loading (see F-G section in Figure 7).

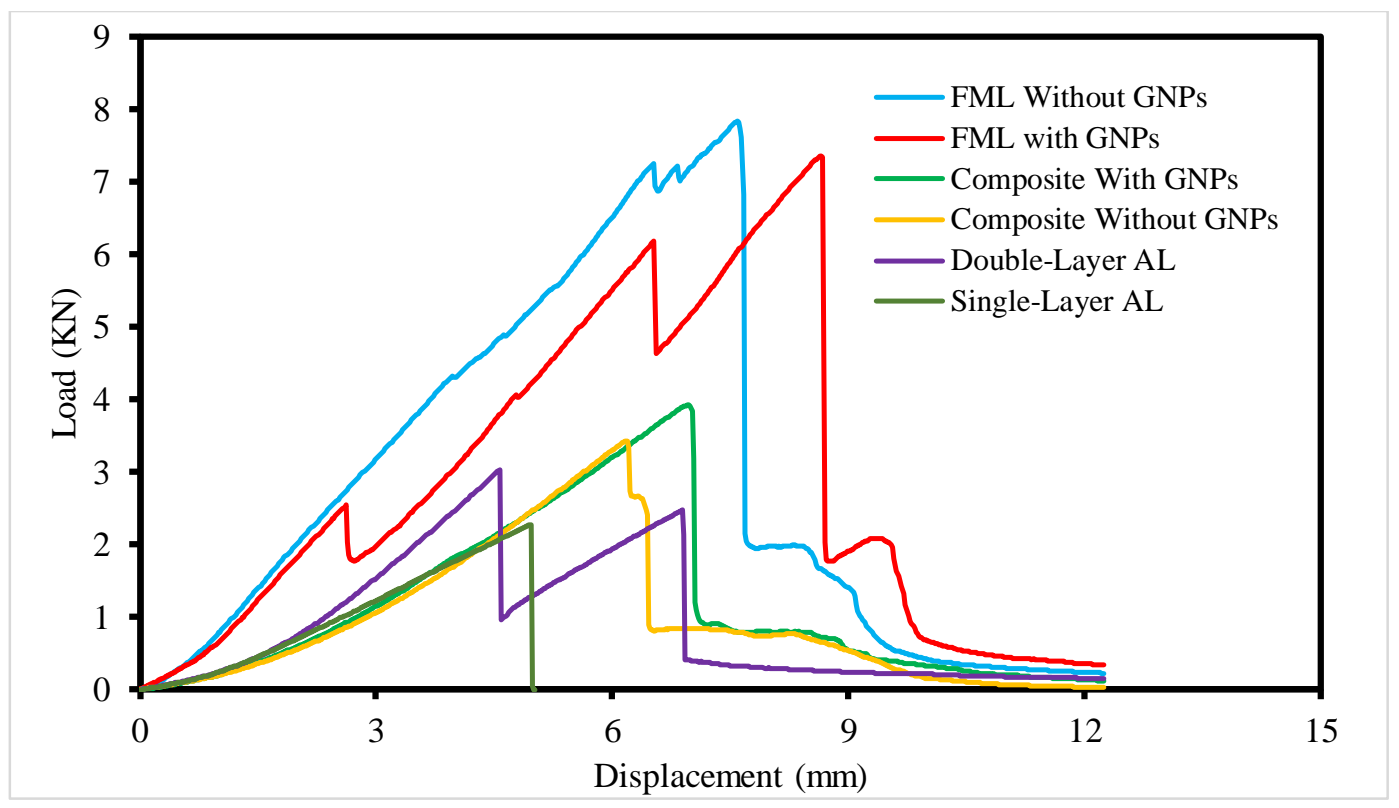

Figure 18. The load-displacement curves of specimens under quasi-static indentation test.

Impact damage is an important failure type of aircraft structures, which can come from a variety of sources, such as a low velocity or high velocity impact. ${ }^{22}$ The low velocity impact occurs through damage from for example service trucks, cargo containers and dropped tools during maintenance operations. $^{3}$ On the other hand, quasi-static indentation loading can be considered similar to low velocity impacts. ${ }^{42}$ The results indicated that despite the enhancement in composite behavior, the addition of GNPs into FML led to a negative effect in indentation test, so it is not recommended to add the GNPs into FML.

\subsection{Energy absorption and interaction effect analysis}

The energy absorption in the composite and FML panels includes three sections: 1) elastic energy, 2) absorbed energy in damage region and 3) energy dissipation by frictional motion. Also, the similar result was shown by Bulut et al. ${ }^{43}$ for hybrid composite specimens. As previously indicated, the damage mechanisms under punch loading were localized, whereas in the indentation loading, in addition to the local mechanisms, global mechanisms also occurred. It can be seen that in the Figure 19 and Figure 20, the existence of global mechanisms in the indentation test has led to an increase in 
energy absorption and SEA compared to the punch loading. As an example, the SEA was increased by $73 \%$ in the modified FML under indentation test as compared to that in punch test.

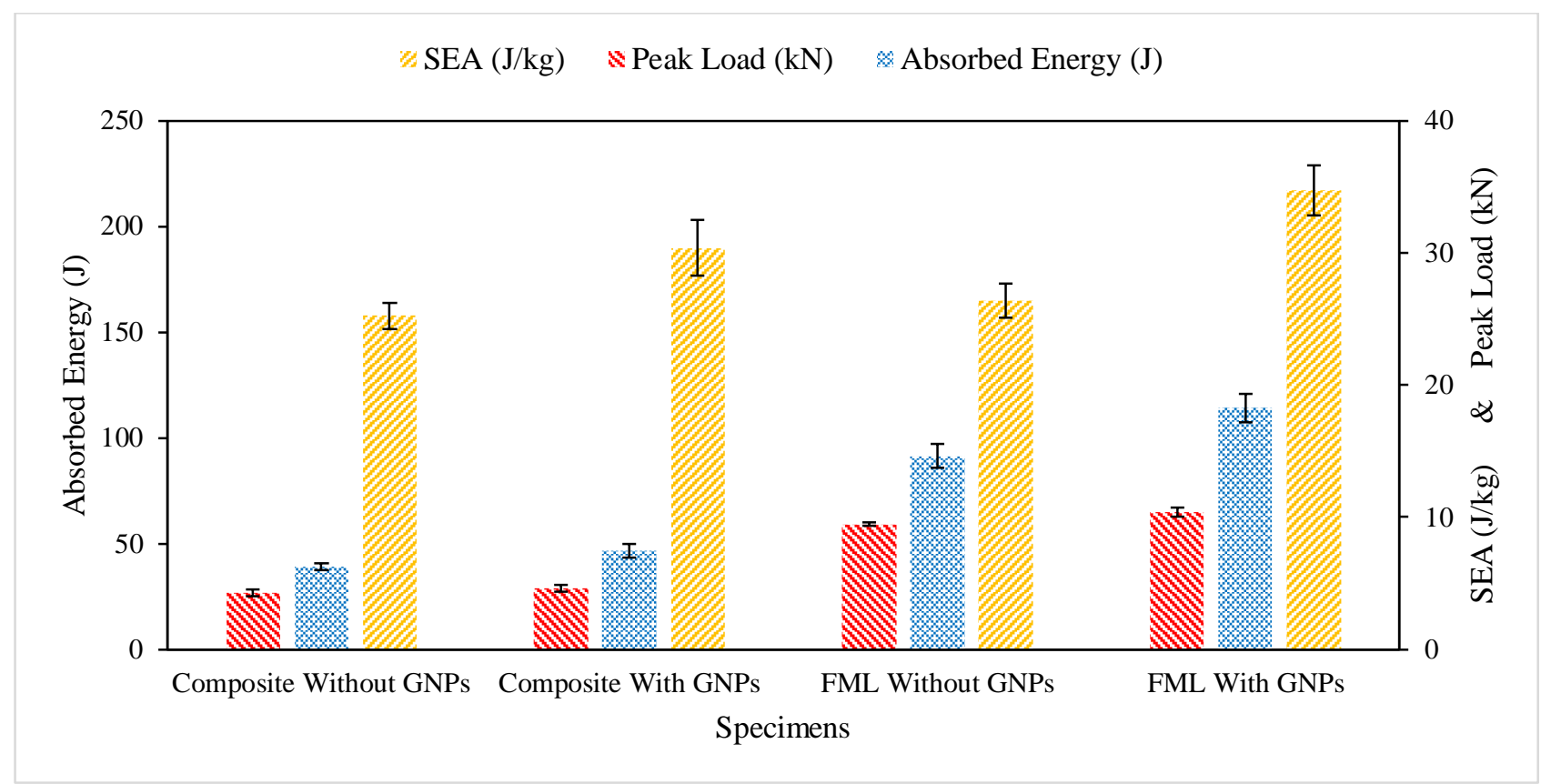

Figure 19. The comparison of the punch loading response of specimens.

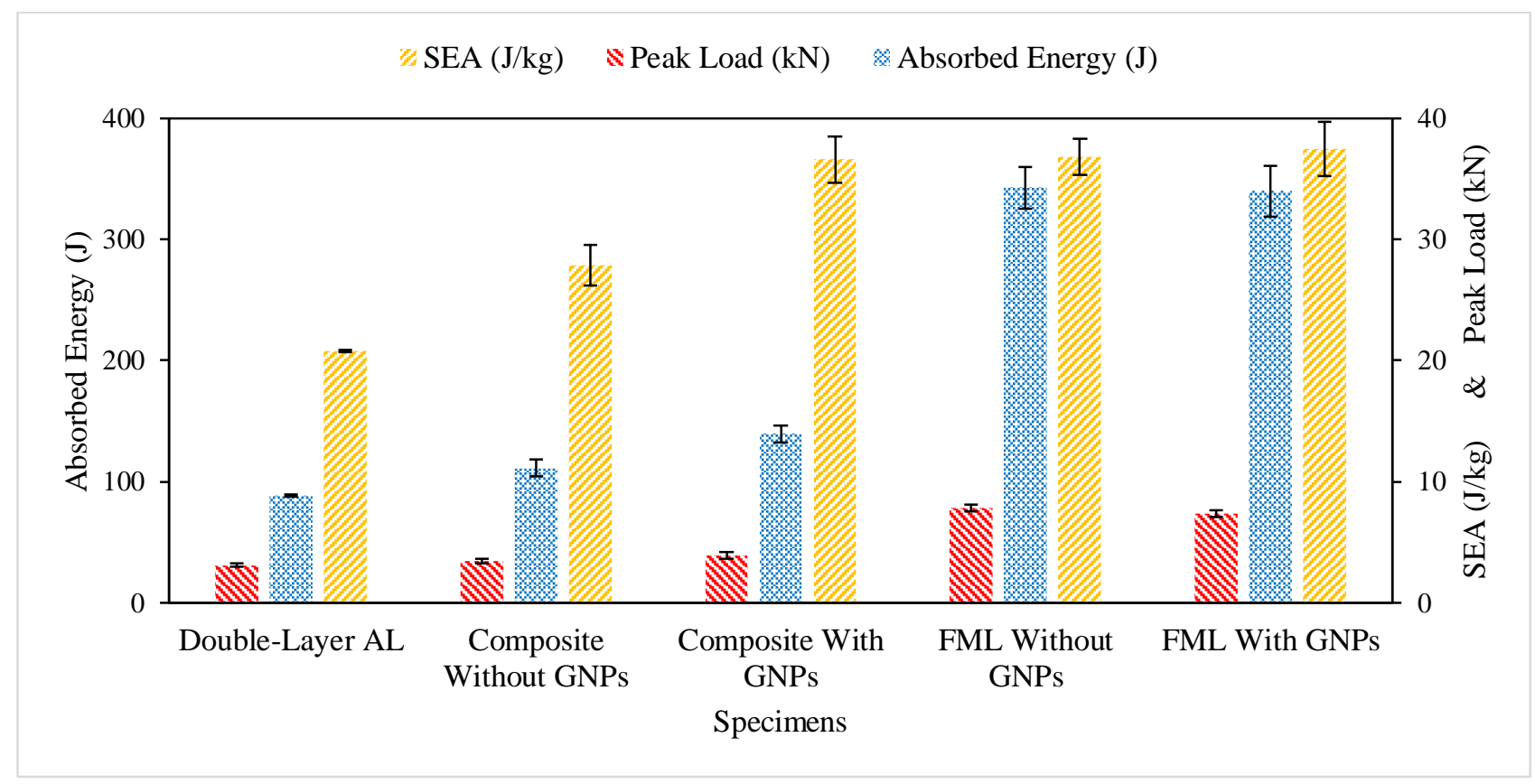

Figure 20. The comparison of the indentation loading of specimens.

The investigated FML panels were made from two AL layers, as well as an unmodified or modified composite laminate. One of the most important reasons for using FML panel in industrial applications is its greater energy absorption compared to the total absorbed energy of the individual components. 
This can be attributed to the existence of interaction effect between AL and composite layers. In other words, the effect of interaction makes the indenter more difficult to penetrate into FML panel than its individual components. ${ }^{44}$ The interaction effect (IE) and interaction effect ratio (IER) are calculated as follows

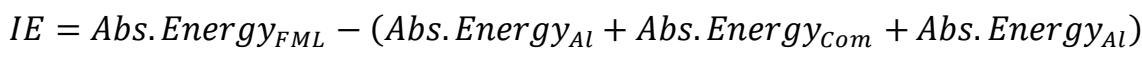

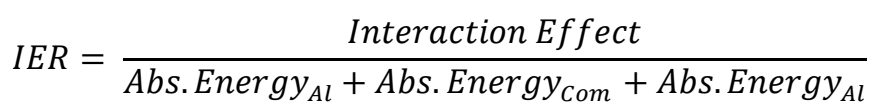

It should be noted that the higher the IER, the more energy is absorbed through the interaction effect. The amount of the IE and IER is reported in Table 3. The IER in unreinforced and reinforced FMLs under punch loading is $21 \%$ and $38 \%$, respectively, which implies that the incorporation of GNPs improves the interaction effect. This improvement was expected to be observed under the indentation loading, but due to the debonding that occurred in the reinforced specimen, adding the GNPs has a negative effect on the IER. In other words, the addition of GNPs into the FML panel reduced the value of IE from $12.35 \mathrm{~J}$ to $9.25 \mathrm{~J}$ and the IER from $56 \%$ to $37 \%$. It should be mentioned that, similar debonding was also observed in the FML specimen under punch loading; but since the damage mechanisms were localized in this test, the debonding did not affect the IE.

On the other hand, the IER in unmodified FML is $21 \%$ under the punch test and $56 \%$ under the indentation loading, as provided in Table 3. This indicates that the presence of the global mechanisms in indentation test makes the interaction effect more evident.

Table 3. Interaction effect of modified and unmodified specimens under indentation and punch loading.

\begin{tabular}{|c|c|c|c|c|c|}
\hline & & \multicolumn{4}{|c|}{ Absorbed Energy (J) } \\
\hline \multirow{2}{*}{\multicolumn{2}{|c|}{ Components }} & \multicolumn{2}{|c|}{ Punch Loading } & \multicolumn{2}{|c|}{ Indentation Loading } \\
\hline & & Without GNPs & With GNPs & Without GNPs & With GNPs \\
\hline & Upper AL layer & $2.90 \pm 0.06$ & $2.90 \pm 0.06$ & $5.41 \pm 0.10$ & $5.41 \pm 0.10$ \\
\hline & Glass/Epoxy8 & $6.26 \pm 0.28$ & 7. $47 \pm 0.50$ & $11.13 \pm 0.72$ & $13.94 \pm 0.68$ \\
\hline$\square$ & Lower AL layer & $2.90 \pm 0.06$ & $2.90 \pm 0.06$ & $5.41 \pm 0.10$ & $5.41 \pm 0.10$ \\
\hline \multicolumn{2}{|c|}{ Sum of Individual components } & $\mathbf{1 2 . 0 6} \pm 0.29$ & $\mathbf{1 3 . 2 7} \pm 0.51$ & $21.93 \pm 0.73$ & $24.74 \pm 0.69$ \\
\hline & FML & $14.64 \pm 0.89$ & $18.28 \pm 1.09$ & $34.28 \pm 1.72$ & $33.99 \pm 2.09$ \\
\hline \multicolumn{2}{|c|}{ IE } & $2.58 \pm 0.94$ & $\mathbf{5 . 0 1} \pm 1.20$ & $\mathbf{1 2 . 3 5} \pm 1.87$ & $9.25 \pm 2.20$ \\
\hline \multicolumn{2}{|c|}{ IER } & $21 \%$ & $38 \%$ & $56 \%$ & $37 \%$ \\
\hline
\end{tabular}


For the purpose of examining the influence of the local and global mechanisms on the energy absorption, the value of local and global energy are individually reported in Table 4. By comparing the $E_{G}$ with $E_{L}$ in the unmodified composite panel, it turns out that the energy dissipation by the global mechanisms is less than that by the local mechanisms. And also, a similar result is observed with the modified composite panel. This can be related to the fact that maximum elongation of E-glass/epoxy composites is no more than 2 percent, implying that composite is low in ductility, therefore the major damages in composite panels are localized.

On the contrary, for the unmodified FML, $E_{G}$ is more than $E_{L}$ which means that more energy is absorbed by the global mechanisms than local ones. This may be attributed to two reasons: firstly, as discussed previously, the interaction effect in indentation loading is greater than that in punch loading. It implies that the interaction effect in global mechanisms is more evident than that in local mechanisms. Secondly, the intrinsic toughness of aluminum alloy (percent elongation of aluminum is about $18 \%$ ) allows the AL layers to absorb energy through plastic deformation and since the plastic deformation in global mechanisms is greater, $E_{G}$ is higher than $E_{L}$. Nevertheless, in the reinforced FML, due to the debonding between AL layer and the composite laminate, the $\mathrm{E}_{\mathrm{G}}$ is less than $\mathrm{E}_{\mathrm{L}}$.

Table 4. The amount of the local and global energy effects.

\begin{tabular}{lcc}
\hline \multicolumn{1}{c}{ Specimens } & $\begin{array}{c}\text { Local Effect } \\
\mathrm{E}_{\mathrm{L}}(\mathrm{J})\end{array}$ & $\begin{array}{c}\text { Global Effect } \\
\mathrm{E}_{\mathrm{G}}(\mathrm{J})\end{array}$ \\
\hline Unmodified Composite & $6.26 \pm 0.28$ & $4.87 \pm 0.77$ \\
Modified Composite & $7.24 \pm 0.50$ & $6.54 \pm 0.84$ \\
Unmodified FML & $14.64 \pm 0.89$ & $19.64 \pm 1.94$ \\
Modified FML & $18.28 \pm 1.09$ & $15.71 \pm 2.36$ \\
\hline$* \mathrm{E}_{\mathrm{P}}=$ Energy absorption in punch loading \\
$* \mathrm{E}_{\mathrm{I}}=$ Energy absorption in indentation loading \\
$* \mathrm{E}_{\mathrm{L}}=\mathrm{E}_{\mathrm{P}}$ \\
$* \mathrm{E}_{\mathrm{G}}=\mathrm{E}_{\mathrm{I}}-\mathrm{E}_{\mathrm{P}}$
\end{tabular}

\section{Conclusions}

The effect of incorporation of GNPs on the quasi-static behavior of composite and FML panels was experimentally investigated in this study. The unmodified and modified panels were fabricated and tested under quasi-static punch and indentation loading. The GNPs were added to epoxy resin with a concentration of $0.2 \mathrm{wt} \%$ and reinforced epoxy was used in the fabrication of the composite and FML panels. The results showed that adding GNPs increased the strength and fracture toughness of specimens by delaying failure modes, though it had an insignificant effect on the modulus of elasticity as compared to the unmodified ones. 
In the punch loading, it was observed that an improvement in maximum displacement, peak load and SEA was achieved in composite by the incorporation of GNPs, and also in the FML, the peak load and SEA were increased by $16.0 \%$ and $31.7 \%$, respectively. Moreover, the results of the indentation test indicated that mentioned mechanical parameters were increased as well for the composite specimen, but in the FML, despite the increase of maximum displacement, the SEA did not change significantly and the peak load was decreased. The reduction of the peak load in modified FML was attributed to the debonding at the composite laminate and AL layer interface.

Additionally, in the FML panels, following damage modes were observed: plastic deformation, matrix cracks, AL and fiber failure, debonding at the composite-AL interface, and delamination in glass/epoxy laminate. These damage modes were similar in both tests, except that the damage mechanisms under punch loading were localized, whereas in the indentation loading, in addition to the local mechanisms, global mechanisms also occurred.

Furthermore, results showed that the interaction effect between AL and composite layers made the FML absorb more energy compared to its individual components. It was observed that incorporation of GNPs improved the interaction effect in punch loading, but in the indentation loading, due to the debonding, adding the GNPs had a negative effect.

\section{Declaration of conflicting interests}

The author(s) declared no potential conflicts of interest with respect to the research, authorship, and/or publication of this article.

\section{Funding}

The author(s) received no public fund or financial support for the research, authorship, and/or publication of this article.

\section{ORCID iD}

Gholamhossein Liaghat https://orcid.org/0000-0003-1925-0643 


\section{References}

1. Vlot A. Impact properties of fibre metal laminates. Compos Eng 1993; 3: 911-927.

2. Ahmadi H, Sabouri H, Liaghat G, et al. Experimental and numerical investigation on the high velocity impact response of GLARE with different thickness ratio. Procedia Engineering 2011; 10: 869-874.

3. Vlot A, Gunnink JW. Fibre metal laminates: an introduction. Dordrecht: Springer Netherlands, 2001.

4. Chai GB, Manikandan P. Low velocity impact response of fibre-metal laminates - A review. Compos Struct 2014; 107: 363-381.

5. Alderliesten R. On the Development of Hybrid Material Concepts for Aircraft Structures. Recent Patents Eng 2009; 3: 25-38.

6. Ahmadi $\mathrm{H}$, Liaghat $\mathrm{G}$, Sabouri $\mathrm{H}$, et al. Investigation on the high velocity impact properties of glass-reinforced fiber metal laminates. J Compos Mater 2013; 47: 1605-1615.

7. Vermeeren CAJR. An Historic Overview of the Development of Fibre Metal Laminates. Applied Composite Materials 2003; 10: 189-205.

8. Vlot A. Low-velocity impact loading: On fibre reinforced aluminium laminates (ARALL and GLARE) and other aircraft sheet materials. Delft: Delft University of Technology, 1993.

9. Vlot A. Impact loading on fibre metal laminates. Int J Impact Eng 1996; 18: 291-307.

10. Vlot A, Krull M. Impact damage resistance of various fibre metal laminates. Le J Phys IV 1997; 07: C3-1045-C3-1050.

11. Liu Y, Liaw B. Effects of constituents and lay-up configuration on drop-weight tests of fibermetal laminates. Appl Compos Mater 2010; 17: 43-62.

12. Seyed Yaghoubi A, Liu Y, Liaw B. Stacking sequence and geometrical effects on low-velocity impact behaviors of Glare 5 (3/2) fiber-metal laminates. J Thermoplast Compos Mater 2012; 25: $223-247$.

13. Meng X, Yao L, Wang C, et al. Investigation on the low-velocity impact behaviour of nonsymmetric FMLs - experimental and numerical methods. Int J Crashworthiness 2020; 0: 119.

14. Subramaniam K, Dhar Malingam S, Feng NL, et al. The effects of stacking configuration on the response of tensile and quasi-static penetration to woven kenaf/glass hybrid composite metal laminate. Polym Compos 2019; 40: 568-577.

15. Arhore EG, Yasaee M. Lay-up optimisation of fibre-metal laminates panels for maximum impact absorption. J Compos Mater 2020; 54: 4591-4609.

16. Sadighi M, Alderliesten RC, Benedictus R. Impact resistance of fiber-metal laminates: A review. Int J Impact Eng 2012; 49: 77-90.

17. Sharma AP, Khan SH. Influence of metal layer distribution on the projectiles impact response of glass fiber reinforced aluminum laminates. Polym Test 2018; 70: 320-347.

18. Compston $\mathrm{P}$, Cantwell WJ, Jones $\mathrm{C}$, et al. Impact perforation resistance and fracture 
mechanisms of a thermoplastic based fiber-metal laminate. J Mater Sci Lett 2001; 20: 597599.

19. Khoramishad H, Alikhani H, Dariushi S. An experimental study on the effect of adding multiwalled carbon nanotubes on high-velocity impact behavior of fiber metal laminates. Compos Struct 2018; 201: 561-569.

20. Megahed M, Abd El-baky MA, Alsaeedy AM, et al. An experimental investigation on the effect of incorporation of different nanofillers on the mechanical characterization of fiber metal laminate. Compos Part B Eng 2019; 176: 107277.

21. Khurram AA, Hussain R, Afzal H, et al. Carbon nanotubes for enhanced interface of fiber metal laminate. Int J Adhes Adhes 2018; 86: 29-34.

22. Zhang H, Gn SW, An J, et al. Impact behaviour of GLAREs with MWCNT modified epoxy resins. Exp Mech 2014; 54: 83-93.

23. Jin $\mathrm{K}$, Wang $\mathrm{H}$, Tao $\mathrm{J}$, et al. Interface strengthening mechanisms of Ti/CFRP fiber metal laminate after adding MWCNTs to resin matrix. Compos Part B Eng 2019; 171: 254-263.

24. Abd El-baky MA, Attia MA. Experimental study on the improvement of mechanical properties of GLARE using nanofillers. Polym Compos 2020; 41: 4130-4143.

25. Logesh K, Hariharasakthisudhan P, Rajan BS, et al. Effect of multi-walled carbon nano-tube on mechanical behavior of glass laminate aluminum reinforced epoxy composites. Polym Compos 2020; 1-12.

26. Eslami-Farsani R, Aghamohammadi H, Khalili SMR, et al. Recent trend in developing advanced fiber metal laminates reinforced with nanoparticles: A review study. J Ind Text 2020; 1528083720947106.

27. Li L, Lang L, Khan S, et al. Investigation into effect of the graphene oxide addition on the mechanical properties of the fiber metal laminates. Polym Test 2020; 91: 106766.

28. Papageorgiou DG, Kinloch IA, Young RJ. Mechanical properties of graphene and graphenebased nanocomposites. Prog Mater Sci 2017; 90: 75-127.

29. Domun N, Kaboglu C, Paton KR, et al. Ballistic impact behaviour of glass fibre reinforced polymer composite with 1D/2D nanomodified epoxy matrices. Compos Part B Eng 2019; 167: 497-506.

30. Chandrasekaran S, Seidel C, Schulte K. Preparation and characterization of graphite nanoplatelet (GNP)/epoxy nano-composite: Mechanical, electrical and thermal properties. Eur Polym J 2013; 49: 3878-3888.

31. Rafiee MA, Rafiee J, Wang Z, et al. Enhanced mechanical properties of nanocomposites at low graphene content. ACS Nano 2009; 3: 3884-3890.

32. Domun N, Hadavinia H, Zhang T, et al. Improving the fracture toughness properties of epoxy using graphene nanoplatelets at low filler content. Nanocomposites 2017; 3: 85-96.

33. Lee C, Wei X, Kysar JW, et al. Measurement of the elastic properties and intrinsic strength of monolayer graphene. Science (80- ) 2008; 321: 385-388.

34. Hosseini Abbandanak SN, Abdollahi Azghan M, Zamani A, et al. Effect of graphene on the interfacial and mechanical properties of hybrid glass/Kevlar fiber metal laminates. J Ind Text 
$2020 ; 1528083720932222$.

35. Keshavarz R, Aghamohammadi H, Eslami-Farsani R. The effect of graphene nanoplatelets on the flexural properties of fiber metal laminates under marine environmental conditions. Int $J$ Adhes Adhes 2020; 103: 102709.

36. Umer R, Li Y, Dong Y, et al. The effect of graphene oxide (GO) nanoparticles on the processing of epoxy/glass fiber composites using resin infusion. Int J Adv Manuf Technol 2015; 81: 2183-2192.

37. Asadi S, Liaghat G, Bahramian A. Experimental investigation of the effect of adding graphene on the mechanical properties of polymer nanocomposite at different strain rates. MSc Thesis, Tarbiat Modares University, Iran, 2017.

38. Bishopp J. Chapter 4 Surface pretreatment for structural bonding. Handb Adhes Sealants 2005; 1: 163-214.

39. Tarpani ACSP, Barreto TA, Tarpani JR. Fatigue failure analysis of riveted fibre-metal laminate lap joints. Eng Fract Mech 2020; 239: 107275.

40. Pranesh R, Hemanathan M, Kiran Babu KM, et al. Mechanical characterization of glass fiber aluminium reinforced riveted joints. FME Trans 2017; 45: 89-92.

41. Liang Y, Wang H, Soutis C, et al. Progressive damage in satin weave carbon/epoxy composites under quasi-static punch-shear loading. Polym Test 2015; 41: 82-91.

42. Airoldi A, Vesco M, Van Der Zwaag S, et al. Damage in GLARE laminates under indentation loads: Experimental and numerical results. ICCM Int Conf Compos Mater.

43. Bulut M, Erkliğ A, Yeter E. Hybridization effects on quasi-static penetration resistance in fiber reinforced hybrid composite laminates. Compos Part B Eng 2016; 98: 9-22.

44. Hassanpour Roudbeneh F, Liaghat G, Sabouri H, et al. Experimental investigation of quasistatic penetration tests on honeycomb sandwich panels filled with polymer foam. Mech Adv Mater Struct 2018; 0: 1-13. 